Revista de Derecho

de la Pontificia Universidad Católica de Valparaíso

LV (Valparaíso, Chile, 2do semestre de 2020)

[pp. 157-193]

\title{
MinERÍA EN TERRITORIO INDÍGENA: ANALIZANDO LA AUSENCIA DE CONSULTA EN EL OTORGAMIENTO DE CONCESIONES MINERAS EN CHILE
}

[Mining in Indigenous Territory: Analyzing the Absence of Consultation in the Granting of Mining Concessions in Chile]

\section{Cristóbal Carmona Caldera* \\ Universidad Diego Portales}

\begin{abstract}
RESUMEN
El objetivo del presente artículo es determinar si la falta de consulta a los grupos indígenas al momento de otorgar concesiones mineras en Chile se encuentra legalmente justificada o si puede entenderse como un incumplimiento de la obligación establecida en el art. $15 \mathrm{No} 2$ del Convenio No169 de la OIT. Para ello se identifican y analizan los principales argumentos utilizados para justificar esta omisión y se procede a examinar la aplicabilidad de la regla de consulta del art. $15 \mathrm{No} 2$ al régimen concesional minero. La conclusión es que el Estado está incumpliendo su obligación convencional en la materia.
\end{abstract}

AbstraCt

The objective of this article is to determine if the lack of indigenous consultation to native population before the granting of mining concessions in Chile is legally justified or if it can be understood as a breach of the obligation established in art. 15 No. 2 of ILO Convention 169. In order to achieve this objective, the three main arguments used to justify this omission are identified and analyzed. Then, we proceed to examine the applicability of the rule of consultation of art. $15 \mathrm{No} 2$ to the mining concession regime. The conclusion is that the State is breaching its conventional obligation on the matter.

* Licenciado en Ciencias Jurídicas y Sociales de la Universidad de Chile, Abogado. Mg. en Estudios Filosóficos (UAH, Chile), Mg. en Derechos Humanos y Democratización (UNSAM/Argentina) y Candidato a Doctor en Derecho por la Universidad Diego Portales (Chile). Investigador Adjunto y profesor de la cátedra Derecho Indígena en la Universidad Diego Portales. Agradezco a Domingo Lovera por los comentarios realizados a lo largo de la realización de una primera versión de este escrito y a Dominique Hervé, Juan Jorge Faundes y Judith Schönsteiner por aquellos efectuados a una versión ya concluida del mismo. Asimismo, agradezco a Álvaro Durán, Carolina Nahuelhual, Alejandro Navarrete, Hellen Pacheco, Carolina Sagredo, Gonzalo Sánchez y Judith Schönsteiner por su referencia -y ayuda para acceder- a distintos informes, artículos de doctrina y jurisprudencia durante el desarrollo de la presente investigación. Por supuesto, los errores que puedan haber en ella son de mi exclusiva responsabilidad. 
Palabras clave

Concesiones mineras - derecho a consulta - exploración y explotación de recursos naturales en territorio indígena - pueblos Indígenas.

\section{Key Words}

Duty to consult - exploration and exploitation of natural resources in indigenous territory - Indigenous Peoples - mining concessions.

RECIBIDO el 6 de julio de 2020 y ACEPTADO el 1 de marzo de 2021

\section{INTRODUCCIÓN}

En Chile, actualmente el derecho a consulta del Convenio No169 de la OIT (Convenio) es considerado una regla "indubitada y forma parte del marco regulatorio aplicable a recursos naturales de dominio público y

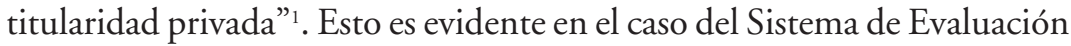
de Impacto Ambiental (SEIA). El art. 85 del Reglamento del Sistema de Evaluación de Impacto Ambiental (RSEIA) establece la necesidad de efectuar un Proceso de Consulta con los Pueblos Indígenas (PCPI) durante la evaluación ambiental de proyectos de inversión ${ }^{2}$. A su vez, en aplicación del Reglamento General de Consulta (RGC), este derecho se ha considerado procedente en diversos procesos relativos a la exploración y explotación de recursos naturales, como en las concesiones de explotación de energía geotérmica ${ }^{3}$, en la modificación de áreas apropiadas para el ejercicio de la acuicultura $^{4} y$, recientemente, en las solicitudes de exploración de aguas subterráneas 5 .

Sin embargo, esta presencia de la consulta en la regulación del uso de los recursos naturales pierde eficacia cuando se trata de concesiones mineras. En efecto, a diez años de la entrada en vigencia del Convenio en

${ }^{1}$ Hervé, Dominque, Justicia Ambiental y Recursos Naturales (Santiago, Ediciones Universitarias de Valparaíso, 2015) p. 287.

2 Para un análisis general, ver DURÁN, Álvaro, El derecho a consulta de los pueblos indigenas en el Sistema de Evaluación de Impacto Ambiental chileno, su estándar a la luz de la jurisprudencia nacional e internacional, en Revista de Derecho Universidad Finis Terrae II (2014) 2, pp. 101-161.

${ }^{3}$ Para una exposición y análisis crítico, ver CARMOnA, Cristóbal, The Road Less Travelled: The Duty to Consult and the Special Rule of Article 15.2 of ILO Convention 169 in the Case of Geothermal Energy Concessions in Chile, en Journal of Energy \& Natural Resources Law 35 (2017) 4, pp. 485-501 [doi: https://doi.org/10.1080/026 46811.2017.1355966].

${ }^{4}$ Subsecretaría de Pesca y Acuicultura, Informe Técnico (D.AC) No877/2017. Propuesta de nuevos sitios de Áreas Apropiadas para el ejercicio de la Acuicultura (A.A.A.) en la XII Región de Magallanes y de la Antártica Chilena, 15 de septiembre de 2017.

${ }^{5}$ Corte de Apelaciones de Antofagasta, Rol No14-2019, 30 de octubre de 2020. 
Chile, estas medidas no están siendo consultadas. La ausencia de consulta a nivel concesional queda de manifiesto en la última solicitud directa que efectuara la Comisión de Expertos en la Aplicación de Convenios y Recomendaciones (CEACR) de la OIT al Gobierno de Chile, publicada el año 2019. En ella, el órgano de la OIT le pide "nuevamente" al Gobierno -pues ya lo había hecho en numerosas ocasiones anteriores- que tomase "las medidas necesarias (inclusive legislativas) para que los pueblos indígenas sean consultados antes de que se otorguen concesiones de exploración o explotación mineras en las tierras que tradicionalmente ocupan"6.

Aunque relativamente previsible desde un paradigma de desarrollo económico de corte extractivista como el chileno ${ }^{7}$, esta ausencia de consulta en las concesiones mineras resulta, prima facie, sorprendente. A nivel normativo, sorprende porque el Convenio contiene una regla expresa ordenando la realización de consulta previa al otorgamiento de autorizaciones para la exploración y explotación de recursos del subsuelo existentes en territorio indígena. En efecto, su art. $15 \mathrm{~N}^{\circ} 2$ señala: "En caso de que pertenezca al Estado la propiedad de los minerales o de los recursos del subsuelo, o tenga derechos sobre otros recursos existentes en las tierras, los gobiernos deberán establecer o mantener procedimientos con miras a consultar a los pueblos interesados, a fin de determinar si los intereses de esos pueblos serian perjudicados, y en qué medida, antes de emprender o autorizar cualquier programa de prospección o explotación de los recursos existentes en sus tierras (...)”. La omisión de este deber se vuelve más grave si se considera que el Convenio es un tratado de derechos humanos ${ }^{9} \mathrm{y}$, por lo tanto, que los derechos contenidos en este instrumento deben ser respetados y promovidos por los órganos del Estado

6 OIT, Solicitud directa (CEACR) - Adopción: 2018, Publicación: 108a reunión CIT (2019) Convenio sobre pueblos indígenas y tribales, 1989 (núm. 169) - Chile (Ratificación : 2008) [https://www.ilo.org/dyn/normlex/es/f?p=1000:1310 0:0::NO:13100:P13100_COMMENT_ID,P11110_COUNTRY_ID,P11110_ COUNTRY_NAME,P11110_COMMENT_YEAR:3962690,102588,Chi le,2018].

7 Ver Merino, Roger, The Cynical State: Forging Extractivism, Neoliberalism And Development in Governmental Spaces, en Third World Quarterly 41 (2020) 1, P. 68, [Doi: 10.1080/01436597.2019.1668264] "The Development model or paradigm of neo-extractivism is formed by the structures and general national and global rules that govern resource extraction. At this level, the only players allowed to influence the model are governing elites, certain state and international agencies, and transnational corporations".

${ }^{8}$ En adelante, todas las citas a artículos en las que no se haga mención expresa a algún cuerpo normativo, deben entenderse como referentes al Convenio.

${ }^{9}$ Ver Tribunal Constitucional, Rol No2387-(2388)-12-CPT (acumuladas), 23 de enero de 2013, considerando $22^{\circ}$. 
(art. 5, Constitución Política de la República (CPR)). A nivel fáctico, la ausencia de consulta en las concesiones mineras llama la atención tanto por la magnitud de los impactos que típicamente tiene la industria minera en las formas de vida indígen $\mathrm{a}^{10}$, como por la creciente conflictividad que ha emergido en torno al otorgamiento y arrendamiento de concesiones mineras en territorios indígenas en los últimos años ${ }^{11}$.

En este contexto, el Estado chileno ha esgrimido una serie de argumentos jurídicos intentado justificar la falta de consulta a las concesiones mineras. Las principales razones aducidas a este respecto son cuatro, a saber: la homologación de la consulta del Art. $15 \mathrm{No} 2$ con otros procedimientos internos; la aplicación de la regla de consulta del art. 6 del Convenio al caso de las concesiones mineras; la pretendida "no autoejecutabilidad" de la norma de consulta del art. 15 No2; y la existencia de un PCPI durante la evaluación ambiental de los proyectos mineros. Se trata de argumentos de distinta naturaleza, los que han sido utilizados con diversa intensidad en diversos periodos. Ahora bien, el que se aduzcan justificaciones legales para la no ejecución de los derechos del Convenio no es inusual. Las propias características de los enunciados normativos de este tratado han significado que el proceso de implementación del Convenio en América Latina suponga una disputa en torno a la determinación de la naturaleza de las normas internacionales y de sus regulaciones internas ${ }^{12}$. Por ende, la cuestión es que tan plausibles son dichos argumentos, jurídicamente hablando.

Frente a ello, el objetivo del presente este artículo es analizar el fundamento legal de los argumentos indicados en el párrafo anterior. En otras

${ }^{10}$ Ver, por ejemplo, CALDERón, Matías, et al., Gran minería y localidades agrícolas en el norte de Chile: comparación exploratoria de tres casos, en Chungará. Revista de Antropología Chilena 48 (2016) 2, pp. 295-305.

11 Por ejemplo, la oposición generada al otorgamiento de concesiones de exploración minera en territorio mapuche williche (AgUAS, Javier y NaHUELPAN, Héctor, Los limites del reconocimiento indígena en Chile neoliberal. La implementación del Convenio 169 de la OIT desde la perspectiva de dirigentes Mapuche Williche, en CUHSO 29 (2019) 1, pp. 108-130); y la impugnación judicial del acuerdo entre Corfo y SQM para continuar con la explotación del Salar de Atacama (Ver Carmona, Cristóbal y Schönsteiner, Judith, Amicus Curiae del Centro de Derechos Humanos de la Universidad Diego Portales, en el caso "Asociación Indígena Consejo de Pueblos Atacameños/Sqm Potasio S.A.”, 2018 [visible en internet: http://www. derechoshumanos.udp.cl/derechoshumanos/images/Carmona_Schonsteiner_ Amicus_Caso_SQM_2018.pdf]).

12 Larsen, Peter, Contextualising Ratification and Implementation: A Critical Appraisal of ILO Convention 169 From a Social Justice Perspective, en The International Journal of Human Rights 24 (2020) 2-3, p. 96 [doi: https://doi.org/10.1080/13642 987.2019.1677613]. 
palabras, determinar si la ausencia de consulta está legalmente justificada desde el punto de vista del derecho interno o si, en cambio, supone una situación de incumplimiento de una obligación convencional que, desde el año 2009, es "ley de la República"13. La conclusión, se puede adelantar, es que las razones esgrimidas para intentar excusar al Estado de su obligación no son jurídicamente plausibles y que, en consecuencia, el derecho a consulta -específicamente la regla contenida en el art. $15 \mathrm{~N}^{\circ} 2$ - constituye una obligación actual y directamente aplicable al régimen concesional minero. En otras palabras, la respuesta a la pregunta planteada es que el Estado de Chile simplemente está incumpliendo la obligación de consulta a las concesiones mineras.

Para sustentar este juicio comenzaré (II) caracterizando los cuatro principales argumentos utilizados en el debate nacional para justificar la falta de consulta previa al otorgamiento de concesiones mineras, explicando en cada caso por qué serían jurídicamente incorrectos desde la perspectiva del propio sistema jurídico nacional. Sobre la base que uno de los resultados del análisis anterior es que la regla de consulta que se debe utilizar en este caso es, prima facie, la contenida en el art. $15 \mathrm{~N}^{\circ} 2$, (III) procederé luego a examinar la aplicabilidad de esta regla al régimen chileno de concesiones mineras, estableciendo que se trata de una obligación plenamente exigible en este contexto. Finalizaré (IV) apuntando brevemente las conclusiones arribadas.

\section{LA FALTA DE CONSULTA A LAS CONCESIONES MINERAS EN CHILE: ANÁLISIS A LAS RAZONES DEL INCUMPLIMIENTO}

Un examen al debate jurídico nacional muestra que son cuatro los principales argumentos que se han utilizado por los tribunales, la Administración y la doctrina para explicar la ausencia de la consulta en el régimen concesional minero. Estos son: (1) que las instituciones jurídicas sectoriales existentes serían suficientes para cumplir con la consulta; (2) que las resoluciones judiciales por las que se constituyen las concesiones no son medidas "administrativas" ni "legislativas" como lo requiere la regla general del art. $6 \mathrm{~N}^{\circ} 1$ (a); (3) que la regla especial del art. $15 \mathrm{No}^{2} 2$ no es directamente aplicable pues tendría el carácter de "no autoejecutable" o "programática"; y (4) que un PCPI a nivel de concesiones no sería procedente dado que los proyectos mineros ya son consultados durante la evaluación ambiental. En los acápites que siguen caracterizaré brevemente

\footnotetext{
${ }^{13}$ Corte de Apelaciones de Concepción, Rol No289-2010, 10 de agosto de 2010, Considerando $7^{\circ}$.
} 
cada uno de estos argumentos, explicando a su vez por qué no pueden ser considerados como jurídicamente plausibles.

\section{La homologación de la consulta con procedimientos internos}

El primer tipo de justificación a analizar, entonces, es aquella que sostiene que "las leyes sectoriales vigentes al momento de la promulgación del Convenio permiten traducir en clave legal doméstica los estándares del mismo" 14 .

El antecedente de esta tesis puede encontrarse en la tramitación parlamentaria del Convenio en la década de los noventa. Recuérdese que en el Mensaje con el que se ingresó el Convenio al Congreso Nacional para su ratificación, se hacía mención a la existencia de ciertas incompatibilidades entre las normas de este tratado y la legislación interna. Dichas incompatibilidades, aclaraba el Mensaje, se solucionarían a través de la formulación de declaraciones interpretativas. Por medio de estas declaraciones, "se podrán precisar las condiciones en que una determinada norma convencional deberá ser interpretada o aplicada"15. Durante la tramitación legislativa del Convenio, se puso en evidencia que el Gobierno tenía pensado formular una declaración general para la gran mayoría de las reglas convencionales. En concreto, se incorporaría una declaración en la que se dijiera que mediante la Ley No19.253 (Ley Indígena) "se está dando cumplimiento a los objetivos que persigue el Convenio" ${ }^{16}$. En otras palabras, que la normativa interna existente permitía dar cumplimiento al Convenio. Sin embargo, al mismo tiempo el Gobierno reconoció como única excepción a esta regla a la norma del art. $15 \mathrm{No} 2$. Respecto a ella manifestó que se harían "las adecuaciones legales internas para establecer el permiso del indigena o de una autoridad para la realización de labores mineras en las tierras indigenas" ${ }^{17}$.

Esta postura que exceptuaba la norma del art. $15 \mathrm{No} 2$ cambiaría con la primera sentencia del Tribunal Constitucional (TC o Tribunal) sobre el Convenio, el año 2000. En este fallo, el Tribunal extiende la lógica implícita en la mencionada declaración interpretativa a la regla especial

${ }^{14}$ Contesse, Jorge y Lovera, Domingo, El Convenio 169 de la OIT en la jurisprudencia chilena: prólogo del incumplimiento, en Anuario de Derecho Público (Santiago, Editorial Universidad Diego Portales, 2011) p. 128.

${ }^{15}$ Gobierno de Chile, Proyecto de Acuerdo relativo al Convenio No 169 sobre pueblos indigenas, adoptado por la Organización Internacional del Trabajo, diciembre 21 de 1990, Boletín No 233-10 [https://www.bcn.cl/historiadelaley/nc/historia-dela-ley/5119/]

${ }^{16}$ Cámara de Diputados, Informe de Comisión de Relaciones Exteriores en Sesión 14. Legislatura 341, 19 de octubre, 1999 [visible en internet: https://www.bcn.cl/ historiadelaley/nc/historia-de-la-ley/5119/].

${ }^{17}$ Cámara de Diputados, cit. (n. 16). 
de consulta del art. $15 \mathrm{~N}^{\circ} 2$. De esta forma, tras expresar que dicha norma tenía un carácter programático, el TC señala que, por lo demás, "una situación similar la contempla, en el actual sistema, el artículo 17 del Código de Minería"18. Luego, agrega que "los procedimientos de consulta del Convenio ya se encuentran incorporados a la legislación interna" ${ }^{19}$, dando como ejemplo de ello a la Participación Ciudadana (PAC) de la Ley de Bases Generales del Medio Ambiente y lo dispuesto en los artículos 10, 11 y 34 de la Ley Indígena. Concluye expresando que "el Código de Minería contempla un claro procedimiento judicial para constituir las concesiones mineras, el que garantiza que todos los interesados pueden ser escuchados frente a una violación de sus derechos" ${ }^{20}$. En suma, para el TC, los procedimientos de participación existentes en el derecho ambiental, indígena y minero, eran suficientes para dar por cumplida la consulta del art. $15 \mathrm{No} 2$.

Este razonamiento tuvo una importante recepción y utilización en los primeros años de vigencia del Convenio. Esto es evidente en el art. 5 de la primera reglamentación de consulta, el ya derogado D.S. No124/2009. Según esa disposición, los proyectos de inversión que se fueran a emplazar en tierras o áreas de desarrollo indígena serían "sometidos a los procedimientos de consulta o participación que se contemplan en las respectivas normativas sectoriales". La misma lógica sería seguida por la Corte Suprema al homologar la consulta con la PAC del SEIA ${ }^{21}$ y por Contraloría General de la República cuando equiparó el procedimiento consultivo a la posibilidad de formular oposiciones a las concesiones eléctricas ${ }^{22}$.

Aun cuando en muchos sentidos esta interpretación parece haber sido abandonada, todavía es posible encontrarla hasta hace algunos pocos años en pronunciamientos de órganos del Estado. En el área de las concesiones mineras, el mejor ejemplo lo constituye la postura expresada por la Comisión Chilena del Cobre (Cochilco) el año 2015, en un oficio a la Cámara de Diputados. En dicho oficio, Cochilco expresa que la legislación minera contiene "disposiciones de mayor fortaleza y énfasis preceptivo que las consagradas en el Convenio $N^{\circ} 169$ de la OIT"23. Esto, puesto que "[m]ientras

\footnotetext{
${ }^{18}$ Tribunal Constitucional, Rol No309-2000, 4 de agosto de 2000, Considerando $70^{\circ}$.

${ }^{19}$ Tribunal Constitucional, Rol No309-2000, 4 de agosto de 2000, Considerando $70^{\circ}$.

${ }^{20}$ Tribunal Constitucional, Rol No309-2000, 4 de agosto de 2000, Considerando $71^{\mathrm{o}}$.

${ }^{21}$ Corte Suprema, Rol No 4078-2010, 14 de octubre de 2010.

${ }^{22}$ Contraloría General de la República, Dictamen No70.292, 17 de diciembre de 2009.

${ }^{23}$ Comisión Chilena del Cobre, Oficio Ord. № 036 de 20 de enero de 2015, p. 2.
} 
el Convenio sólo habla de consultas, o sea de escuchar lo que la comunidad indigena afectada pueda decir, nuestro Código de Minería permite impugnary oponerse a una concesión que le perjudica, especificamente, cuando la mensura ha abarcado, en todo o parte, una o más pertenencias ya constituidas o en trámite (artículos 83 y 84 del Código de Minería) ${ }^{24}$.

Esta noción de hacer equivalente la consulta a la regulación sectorial existente al momento de la entrada en vigencia del Convenio, estimo, es evidentemente errónea. De partida, la dictación del RSEIA y del RGC parecen suficientes para refutar esta idea en lo que se refiere al ámbito de ambiental y administrativo, por cuanto cada uno de estos reglamentos establece un procedimiento autónomo y diferenciado para dar cumplimiento a la consulta. A la misma conclusión se llega cuando se analiza este argumento desde el punto de vista de la legislación minera. La primera de las instituciones mineras que el TC asemeja con la consulta, es aquella contemplada en el artículo 17 del Código de Minería (CM). Este artículo contiene lo que Samuel Lira ha llamado "lugares de interés público de cateo prohibido"25. De acuerdo a esta norma, para poder efectuar "labores mineras" en ciertos lugares -ciudades, parques nacionales, recintos militares, etc.- se requiere de la autorización de determinadas autoridades -gobernadores, intendentes, el Presidente de la República, etc.-. Es difícil comprender qué quería decir el Tribunal con que estos permisos pudiesen representar una "situación similar" al derecho a consulta, pues en ninguna de las instancias del art. 17 la autoridad gubernamental respectiva tiene la obligación de hacer partícipe a la ciudadanía en el proceso de toma de decisión. La única relación que es posible ver entre ambas normas es que al ser los permisos del art. 17 "autorizaciones" para efectuar "labores mineras", por aplicación del art. $15 \mathrm{No} 2$ dichos permisos podrían ser objeto de consulta siempre que las áreas identificadas se superpusiesen a territorio indígena. Pero esta es una vinculación que el Tribunal no hace.

El TC sostenía también que el proceso de constitución de concesiones mineras "garantiza que todos los interesados pueden ser escuchados frente a una violación de sus derechos". Un argumento similar se encuentra en el oficio de Cochilco, el cual refiere que la legislación minera otorga a las comunidades inclusive más protección que el Convenio, pues dota de la capacidad de "impugnar y oponerse" a la concesión que los perjudica. Ambas afirmaciones no solo son erróneas por la manifesta diferencia que existe entre la consulta y el proceso de constitución de concesiones, sino

${ }^{24}$ Comisión Chilena del Cobre, cit. (n. 23) p. 2.

${ }^{25}$ Lira, Samuel, Curso de Derecho de Minería (Séptima edición actualizada, Santiago, Editorial Jurídica de Chile, 2016) pp. 62-65.

${ }^{26}$ LirA, Samuel, cit. (n. 25) p. 64. 
además porque en este último procedimiento prácticamente no existen posibilidades para que los pueblos indígenas puedan "ser escuchados frente a una violación de sus derechos", ni menos que puedan "impugnar y oponerse" a la concesión. Ello, salvo que tengan algún interés minero en juego. Esto es evidente en el procedimiento de constitución de concesiones de exploración, en donde el legislador decidió derechamente no contemplar la posiblidad de oposición ${ }^{27}$. Y si bien en el procedimiento de constitución de concesiones de explotación sí se pueden formular oposiciones, tanto los legitimados como las causales para ello son extremadamente limitadas. En efecto, en lo que toca la oposición a la solicitud de mensura, solo le corresponde acción a quien tenga un pedimento anterior, o una concesión de exploración basada en un pedimento anterior, o una manifestación anterior a la manifestación que se pretende mensurar (art. 61, CM). La oposición a la constitución de la concesión, en tanto, solo podría ser formulada por aquellos titulares de pertenencias constituidas o en trámite que se superpongan con la pertenencia mensurada (art. 84, CM). Por ende, salvo que las comunidades estén en algunas de estas situaciones, no podrán oponerse al otorgamiento de la concesión.

Visto lo anterior, parece claro que la consulta sencillamente no puede ser equiparada a las instituciones y procedimientos mineros existentes. En consecuencia, este argumento no puede utilizarse como una justificación jurídica de la omisión de la consulta previa al otorgamiento de concesiones mineras.

2. La aplicación de la regla general del art. $6 N^{\circ} 1($ a) a las concesiones mineras

Según se vio en la introducción, además de la regla general de consulta del art. $6 \mathrm{No}^{\circ} 1$ (a) el Convenio contiene una regla de consulta especial en el art $15 \mathrm{No}^{\circ}$, relativa a los permisos de exploración y explotación de recursos naturales de titularidad estatal que se encuentren en territorio indígena. A pesar de la existencia de estas dos normas, en Chile el debate y aplicación de la consulta se ha centrado casi exclusivamente en la regla general del art. 6, prácticamente invisibilizando la existencia de la regla del art. 15 . Ha sido la norma del art. 6 la regulada en los diversos reglamentos dictados y es sobre su aplicabilidad que se ha discutido mayormente en tribunales, inclusive en casos que caerían dentro de espectro de la norma del art. $15^{28}$.

${ }^{27}$ LirA, Samuel, cit. (n. 25) p. 118.

${ }^{28}$ Ver, por ejemplo, Bermúdez, Jorge y Hervé, Dominique, La jurisprudencia ambiental reciente: tendencia al reconocimiento de principios y garantismo con los pueblos indigenas, en Anuario de Derecho Público (Santiago, Ediciones Universidad Diego Portales, 2013) p. 252. 
De igual forma, la doctrina le ha dedicado escasa atención en sus análisis a la norma del art. $15 \mathrm{No}^{22}$, queriéndola homologar a la regla del art. $6^{30}$ o supeditando su eficacia a una eventual reforma legislativa ${ }^{31}$.

Uno de los efectos de esta tendencia es que se tiende a extender la aplicabilidad de la norma del art. 6 a hipótesis que manifiestamente caen dentro del ámbito de la del art. 15No2. Esto es lo que sucede en el que quizás es el argumento más común para desestimar la consulta de las concesiones mineras. La consulta, se señala, sería "inaplicable al procedimiento de constitución de concesiones mineras, toda vez, que tal procedimiento de constitución establecido por el Código de Minería de 1983, como lo señala el artículo 34 de dicho cuerpo legal, es una potestad judicial, mas, no legislativa ni administrativa (objetos estas del procedimiento de consulta a que se refiere el Convenio y la norma puntual)" ${ }^{32}$.

Este argumento ha sido utilizado tanto en sede judicial como por parte de los órganos de Administración. En la práctica judicial, independientemente de si las comunidades indígenas invocaron en su reclamo la regla general del art. $6 \mathrm{~N}^{\circ} 1(\mathrm{a})^{33}$ o la especial del $15 \mathrm{No}^{\circ} 2^{34}$, la respuesta de los tribunales ha sido la mayoría de las veces la misma: las concesiones mineras, por constituirse por medio de resoluciones judiciales, no son medidas "legislativas o administrativas" como lo demanda el art. 6. Por tanto, no deben ser consultadas. La Administración, en tanto, ha usado este razonamiento en foros domésticos e internacionales. Entre los primeros, vale mencionar cómo, en una sesión especial de la Cámara de Diputados destinada precisamente a tratar el tema de la falta de consulta a las concesiones mineras, la entonces Ministra de Desarrollo Social intentó

${ }^{29}$ Meza-Lopehandía, Matías, El Convenio No169 sobre pueblos indigenas y tribales de la Organización Internacional del Trabajo, en AYLwin, José (Coord.), Los pueblos indígenas y el derecho (Santiago, LOM, 2013) p. 388.

${ }^{30}$ Donoso, Sebastián, Empresas y comunidades indígenas: el nuevo escenario que plantea el Convenio 169 de la OIT, en Temas de la agenda Pública 9 (2014) 73, p. 14.

${ }^{31}$ Hervé, Dominique y Pérez, Sergio, Adecuación de la legislación interna a los estándares impuestos para la administración de recursos naturales, en CONTESSE, Jorge (Ed.), El Convenio 169 de la OIT y el derecho chileno. Mecanismos y obstáculos para su implementación (Santiago, Ediciones Universidad Diego Portales, 2012) p. 86.

32 Guggiana, María, Fragilidad de los Derechos Mineros en Chile. Análisis Dogmático, Estudio de Casos (Santiago, Editorial Metropolitana, 2016) p. 82. En el mismo sentido, ver Aninat, Isabel, Los desafíos pendientes del Convenio 169, en Puntos de Referencia (2014) 369, p. 5, nota 18.

${ }^{33}$ Corte de Apelaciones de Valdivia, Rol No1091-2014, 23 de abril de 2015, Considerando $5^{\circ}$.

${ }^{34}$ Ver Corte de Apelaciones de Copiapó, Rol Civil No 91- 201712 de diciembre de 2017 y acumuladas 92-2017 y 93-2017, Considerando 6º. 
excusar esta omisión argumentando que ese sería un aspecto que excedería las facultades de su ministerio, dado que dichas concesiones "son sede jurisdiccional de los tribunales de justicia" ${ }^{35}$. Entre los segundos, se puede destacar las respuestas del gobierno chileno a la observaciones efectuadas reiteradamente por la CEACR sobre el incumplimiento del art. 15No2. En estas memorias o informes a la OIT, el Gobierno se limita a contestar que "las concesiones mineras corresponden a medidas judiciales y no medidas administrativas dependientes del Poder Ejecutivo" 36 .

La argumentación expuesta, estimo, es problemática en diversos sentidos. Debe notarse, primero, que aun razonando desde la regla general del art. $6 \mathrm{No}^{\circ} 1$ (a) se podría sostener que las concesiones mineras sí son medidas "administrativas" y, por tanto, consultables. Al respecto, debe recordarse que el otorgamiento concesiones mineras corresponde, según ha dicho la Corte Suprema, a "una actividad administrativa que el constituyente le encarga a los Tribunales de Justicia" ${ }^{37}$. En palabras de Alejandro Vergara, se trataría "funcionalmente de un acto administrativo que ha surgido orgánicamente en sede judicial" 38 . Debido a esta naturaleza "administrativa", las concesiones podrían teóricamente ser subsumidas dentro de la categoría de "medidas administrativas" a las que refiere el art. 6No1(a).

35 Cámara de Diputados, Acta de la sesión 105a, especial, en miércoles 10 de diciembre de 2014. Análisis de la situación que diversas comunidades indígenas han denunciado en relación con el notorio incremento de las concesiones mineras de explotación y exploración constituidas en territorios ocupados por familias y comunidades indigenas, 2014 [visible en internet: https://www.camara.cl/pdf.aspx?prmid=10934 \&prmtipo=TEXTOSESION].

${ }^{36}$ Gobierno de Chile, Memoria 2013. Presentada por el Gobierno de Chile en conformidad con las disposiciones del artículo 22 de la Constitución de la Organización Internacional del Trabajo correspondiente al periodo 2008-2013 acerca de las medidas adoptadas para dar efectividad a las disposiciones del Convenio sobre Pueblos Indígenas yTribales, 1989 (NÚM. 169), ratificado el 15 de septiembre de 2008, 1 de septiembre de 2013, p. 119. Ver también, Gobierno DE Chile, Informe 2016. Presentada por el Gobierno de Chile, en consideración a la solicitud de información formulada en el informe del Director General, en Quinto informe complementario: Informe del Comité establecido para examinar la reclamación en la que se alega el incumplimiento por el Gobierno de Chile del Convenio sobre pueblos indigenas y tribales, 1989 (número 169), presentada en virtud del artículo 24 de la Constitución de la OIT por el Sindicato Interpresas número 1 de Planificadores Mapuche de Santiago, 2016, p. 13.

${ }^{37}$ Corte Suprema, 4 de mayo de 2016, Rol No6.628-15, Sentencia de Reemplazo, Considerando $1^{\circ}$. Para una comprensión diversa de la naturaleza administrativa concesión, ver Ossa, Juan Luis, Tratado de Derecho de Minería (Quinta Edición actualizada y ampliada, Santiago, Editorial Jurídica de Chile, 2012) p. 140.

${ }^{38}$ Vergara, Alejandro, Sistema de Derecho Minero (Santiago, Thomson Reuters, 2013) p. 264. Énfasis original. 
Pero aun si no se comparte esta teoría y se estima que las concesiones mineras son medidas "judiciales" y, por ende, no consultables desde la perspectiva de la regla general de consulta, el argumento bajo análisis sigue siendo problemático. Ello, por cuanto opera desde la premisa que la norma de consulta aplicable a estos casos es la del art. 6No1(a) cuando, en realidad, es la regla de consulta contenida en el art. $15 \mathrm{No} 2$ la que en razón de su especialidad debiese ser la utilizada.

Como parece claro, la regla de consulta del artículo $15 \mathrm{No} 2$ tiene el carácter de lex specialis en relación a la del art. 6No1(a). La máxima lex specialis derogat legi generali, recuérdese, es una técnica de interpretación y solución de conflictos generalmente aceptada en derecho internacional. Según esta, cuando dos o más normas -en este caso contenidas en un mismo tratado- se refieren a la misma materia o asunto, se le debe dar prioridad a aquella que es más específica ${ }^{39}$. Ello, puesto que "al ser más concreta, suele considerar de mejor manera las características particulares del contexto al cual debe aplicarse que cualquier otra regla general" ${ }^{40}$. Que la regla de consulta del artículo $15 \mathrm{No} 2$ tiene el carácter de lex specialis en relación a la del art. $6 \mathrm{No}^{1}$ (a) resulta evidente de la sola comparación de sus enunciados. Así, mientras esta última sería aplicable de manera general a toda medida administrativa o legislativa, la primera responde a una situación particular: cuando el Estado, teniendo la titularidad (o algún otro derecho) sobre recursos naturales existentes en territorio indígena, pretende emprender o autorizar la exploración o explotación de esos recursos. Así, la consulta y las restantes obligaciones contenidas en el art. $15 \mathrm{No}_{2} 2$-cuales son, participación en los beneficios e indemnización por daños- son concebidas por la doctrina como "salvaguardas" específicas para la protección de los derechos colectivos de los pueblos indígenas frente a los efectos perjudiciales que tiene explotación de recursos naturales presentes en su territorio ${ }^{41}$.

Esta especificidad también se manifiesta en la diferencia que existe entre los criterios de procedencia que contienen ambas normas. El art. 6No1(a), se sabe, demanda que las medidas sean "susceptibles de afectar directamente"

${ }^{39}$ International Law Commission, Conclusions of the Work of the Study Group on the Fragmentation of International Law: Difficulties arising from the Diversification and Expansion of International Law, 2006, párr. 5 [http://legal.un.org/docs/?path=../ ilc/texts/instruments/english/draft_articles/1_9_2006.pdf\&lang=EF].

${ }^{40}$ International Law Commission, cit. (n. 39) para. 7. Traducción del autor.

${ }^{41}$ Cabrera, María, The Requirement of Consultation With Indigenous Peoples in the ILO: Between Normative Flexibility and Institutional Rigidity (Leiden, Brill Nijhoff, 2017) p. 45. Esta postura es confirmada por los trabajos preparatorios del Convenio. Ver OIT, Partial Revision of the Indigenous and Tribal Populations Convention, 1957 (No. 107), Report VI (1), 75 ${ }^{\text {th }}$ Session, 1988, p. 58. 
a los pueblos indígenas para que se "gatille" la obligación de consulta ${ }^{42}$. $\mathrm{El}$ art. $15 \mathrm{No} 2$, en cambio, contiene un criterio más amplio. Tal como recientemente ha subrayado la CEACR, en esta norma " $[e]$ l Convenio no contempla como condición para la realización de la consulta la existencia de evidencia de un posible impacto" 43 . Por ende, puede decirse que esta disposición establece una regla objetiva de procedencia ${ }^{44}$ : si los recursos naturales sobre los cuales el Estado otorga autorización para su exploración/explotación se encuentran en territorio indígena, entonces deberá realizarse un proceso de consulta. Y, acá, la consulta tendrá precisamente como fin "determinar si los intereses de esos pueblos serían perjudicados, y en qué medida", como el propio art. $15 \mathrm{~N}$ o2 señala.

Visto lo anterior, resulta claro que el art. $15 \mathrm{No} 2$ es una regla de consulta dirigida a una realidad específica -i.e., los daños comúnmente causados por la industrias extractivas a las formas de vida indígena- y que, respondiendo a esa realidad, contempla un criterio de procedencia particular, más amplio que aquel establecido en el art. 6No1(a). En tanto lex specialis, entonces, es la norma del art. $15 \mathrm{No} 2$ la que debe primar por sobre la regla general cuando las circunstancias sean subsumibles dentro de su supuesto hecho, que es lo que -prima facie, al menos- sucede con las concesiones mineras en Chile ${ }^{45}$. En virtud de ello, se puede concluir que el argumento que descarta la procedencia de la consulta en las concesiones mineras basándose en que estas se constituyen por "resolución judicial", es incorrecto, pues razona desde la norma de consulta equivocada.z

3. La no autoejecutabilidad de la regla de consulta del art. $15 N^{\circ} 2$.

${ }^{42}$ Para un comprensivo y muy buen análisis de este criterio y cómo se debería hacer operativo en Chile, puede revisarse FAUNDES, Juan Jorge, Consulta indígena y centrales de generación hidroeléctrica de menos de $3 M \mathrm{~W}$ : desregulación riesgosa, a la luz del derecho fundamental a la identidad cultural de los pueblos indigenas, en Bozzo, Sebastián, Remeseiro, Rebeca y Esis, Ivette (Coords.), Memorias III Congreso Internacional de Regulación y Consumo (Santiago, Universidad Autónoma de Chile, RIL Editores, 2020) pp. 375-382.

43 OIT, Observación (CEACR) - Adopción: 2019, Publicación: 109a reunión CIT (2020) Convenio sobre pueblos indígenas y tribales, 1989 (núm. 169) - Colombia (Ratificación : 1991) [visible en internet: https://www. ilo.org/dyn/normlex/es/f?p=1000:13100:0::NO:13100:P13100_COMMENT_ ID:4023016].

${ }^{44}$ Para un desarrollo de esta idea, véase Carmona, Cristóbal, cit. (n. 3), pp. 490-495. En el mismo sentido, BArros, Alonso y Schönsteiner, Judith, Diligencia debida: Proyectos de inversión, propiedad sobre los recursos naturales y consulta libre, previa e informada a los pueblos y comunidades indígenas concernidos, en VIAL, Tomás (ed.), Informe Anual sobre Derechos Humanos en Chile 2014 (Santiago, Ediciones UDP, 2014) p. 211.

${ }^{45}$ Ver Sección III. 
Una distinción que ha acompañado desde sus inicios el debate sobre la implementación del Convenio, ha sido aquella formulada por el TC entre normas "autoejecutables" y "no autoejecutables". Las normas no autoejecutables, indicaba el Tribunal, "imponen la obligación al Estado, para que en uso de sus potestades públicas, sancione la normativa necesaria para que por esa vía les dé vigencia efectiva" ". Así, en su concepción original, se trata de obligaciones que no son inmediatamente aplicables por los órganos del Estado, ni directamente exigibles en tribunales, sin la existencia de una legislación o reglamentación previa. En lo que concierne a nuestro tema, mientras el TC declaró que la regla general de consulta del art. 6No1(a) era autoejectuable, al mismo tiempo decidió que la regla especial de consulta del art. $15 \mathrm{No} 2$ tenía un carácter no autojecutable o programático.

Esta declaración de no autoejecutabilidad de la consulta contemplada en el art. $15 \mathrm{No} 2$ ha sido reforzada por la doctrina nacional y utilizada regularmente por los órganos de la Administración. Así, distintos autores y autoras nacionales han indicado que, dado el carácter "programático" 47 que tendría la consulta en materias mineras, para su implementación se requeriría antes de una "reforma legislativa" 48 o de "un acto de implementación posterior" ${ }^{4}$. En lo que concierne a la práctica administrativa cabe relevar, a modo de ejemplo, la postura que sostuvieron por varios años el Ministerio de Minería primero y el Ministerio de Energía después, en el contexto de la consulta a las concesiones de energía geotérmica. Acá, para negar la procedencia de la consulta del art. 6No1(a), ambos ministerios insistieron en que, por tratarse de recursos del subsuelo de titularidad estatal, la norma aplicable a este tipo de energía era la del art. 15No2. No obstante, luego agregaban que esta norma tampoco podía ser aplicada por tener carácter "programático" ${ }^{50}$. En el contexto específico de las concesiones mineras, la no autoejecutabilidad del art. $15 \mathrm{No} 2$ ha sido usada por el gobierno chileno para responder a los cuestionamientos de la CEACR por el incumplimiento a esta norma. Así, en su Memoria del año 2013, el Gobierno indicó que, "si bien en criterio del Tribunal Constitucional (...) [la] referida norma tiene carácter programática, los esfuerzos del Gobierno

${ }^{46}$ Tribunal Constitucional, Rol No309-2000, 4 de agosto de 2000, Considerando $48^{\circ}$.

${ }^{47}$ Hervé, Dominique y Pérez, Raimundo (Coord.), Derecho Ambientaly Politicas Públicas. Cuadernos de Análisis Jurídico, Colección Derecho Ambiental (Santiago, Ediciones UDP, 2011) p. 428.

${ }^{48}$ Hervé Dominique y Pérez, Sergio, cit. (n. 31) p. 86.

${ }^{49}$ Carrasco, Felipe, El derecho minero ante la normativa indigena nacional e internacional (Santiago, Ediciones Jurídicas de Santiago, 2017) p. 267.

${ }^{50}$ Ver Carmona, Cristóbal, cit. (n. 3) pp. 495 y 496. 
han ido encaminados a incorporar en el SEIA la consulta establecida en el artículo 6 del Convenio" ${ }^{1}$. En la misma línea se pronuncia en su informe del año $2016^{52}$.

En lo que se refiere a la práctica judicial en la materia, se debe notar que prácticamente no existen fallos que utilicen la tesis de la no autoejecutabilidad para negar la procedencia de la consulta del art. 15No2. Quizás el ejemplo más cercano lo pueda constituir la sentencia de la Corte Suprema (Corte) en la impugnación del acuerdo entre Corfo y SQM para continuar la explotación del Salar de Atacama. En esta sentencia, al momento de indicar que la aplicabilidad de la consulta del art. 6No1(a) y de la "derivada de lo establecido en el numeral $15 N^{\circ} 2$ del referido convenio" debía ser evaluada por la autoridad correspondiente al momento de la modificación de la Resolución de Calificación Ambiental (RCA), señala que dicha autoridad debía también "en tal procedimiento definir la (...) calidad de normas autoejecutables de ambas, para efecto de establecer la procedencia de aplicación directa" ${ }^{\text {"3. }}$. Acá, aunque la Corte no señala directamente que el artículo $15 \mathrm{~N} 02$ tenga carácter programático, sí pone en suspenso su exigibilidad actual -así como también, extrañamente, la del art. $6 \mathrm{~N}^{\circ} 1$ (a)-, entendiendo que la autoejecutabilidad de esta norma deberá ser determinada en el caso concreto por la autoridad ambiental.

Al revisar este fallo no deja de llamar la atención que todavía al año 2019 se continúe apelando a la distinción "autoejecutabilidad/no autoejecutabilidad" de la consulta del art. $15 \mathrm{No} 2$ para, aunque sea indirectamente, determinar su aplicabilidad en las concesiones mineras. Llama la atención, de partida, porque aun si se aceptara que esta norma especial de consulta tiene carácter programático, la permanente invocación a su no autoejecutabilidad pone en evidencia el hecho que todavía no se ha dictado normativa alguna para darle efecto. Esto supone en sí mismo un incumplimiento del Estado al respecto. Pero la persistencia de este argumento causa sorpresa, principalmente, por lo febles que son los fundamentos jurídicos en los que descansa dicha categorización. En particular, porque a) ella sería contradictoria con el régimen internacional y constitucional para formular reservas y declaraciones interpretativas a los tratados; b) porque la ratio descidendi de las sentencias del TC no tiene fuerza vinculante; $y$, finalmente, c) por la arbitrariedad de la argumentación utilizada por el TC para justificar dicha distinción. A continuación examinaré brevemente cada uno de estos puntos.

\footnotetext{
${ }^{51}$ Gobierno de Chile, Memoria OIT 2013, cit. (n. 36) p.116.

${ }^{52}$ Gobierno de Chile, Informe OIT 2016, cit. (n. 36) p. 13.

${ }^{53}$ Corte Suprema, Rol No 25.142-2018, 22 de abril de 2019, Considerando $8^{\circ}$.
} 
a) Contradicción con el régimen internacional y constitucional. En derecho internacional, los estados pueden formular "reservas" y "declaraciones interpretativas" con el objeto de exceptuarse, modificar o aclarar el contenido de determinadas obligaciones establecidas en los tratados. Esta posibilidad, eso sí, estará supeditada a la regulación específica que sobre el tema disponga cada tratado o, en su defecto, al régimen general establecido en la Convención de Viena sobre el Derecho de los Tratados (CVDT) (arts. 19 a 23). Será el ordenamiento jurídico interno de cada país el que determine la autoridad competente para formularlas.

$\mathrm{Al}$ respecto, habría que comenzar señalando que el régimen de tratados de la OIT tiene dos particularidades que difícilmente serían compatibles con una atribución de no autoejecutabilidad a determinadas normas. Por una parte, en este sistema no se admite la formulación reservas a los trata$\operatorname{dos}^{54}$. Por otra, la Constitución de la OIT impide que la ratificación de un convenio pueda menoscabar derechos que se encuentran garantizados en otros instrumentos nacionales o internacionales (Art. 19No8, Constitución de la OIT) ${ }^{55}$. Ambas características complejizan la posibilidad de efectuar declaraciones que afecten la vigencia de las normas más favorables para los sujetos de protección de los convenios y recomendaciones de la OIT.

Junto a ello, habría que notar que la asignación de los atributos de autoejecutabilidad o no autoejecutabilidad de las normas de un tratado por parte de un tribunal contradice en más de una forma el régimen constitucional chileno en materia de tratados. Primero, porque la formulación de reservas o declaraciones interpretativas "no es una de las atribuciones del Tribunal Constitucional" ${ }_{66}$. La compentencia recae exclusivamente en el Presidente de la República, quien podrá efectuarlas "siempre que ellas procedan de conformidad a lo previsto en el propio tratado o en las normas generales de derecho internacional' (art, 54No1, inc. 30, CPR) -cuestión que, como se dijo en el párrafo anterior, sería normativamente compleja en el caso de los convenios de la OIT-. Segundo, porque si se considera

${ }^{54}$ OIT, Memorandum de la Oficina Internacional del Trabajo sobre la práctica de las reservas en materia de convenios multilaterales, 1951 [visible en internet: https:// www.ilo.org/public/libdoc/ilo/P/09648/09648(1951-34)280-321.pdf].

${ }^{55}$ En virtud de esta norma fue que finalmente el gobierno chileno no pudo hacer la declaración interpretativa que tenía prevista para el art. 35 del Convenio. Véase, Urrejola, Antonia, Aplicación del Convenio No169 en Chile, en De Cea, Maite y Fuentes, Claudio (Eds.), La Consulta Indígena. Colombia-Perú-Chile (Santiago, RiL Editores, 2016) p. 116

${ }^{56}$ NúNÉE, Manuel, Comentario a 'El derecho de consulta previa en el Convenio 169 de la OIT. notas para su implmentación en Chile', en CONTESSE, Jorge (Ed.), El Convenio 169 de la OIT y el derecho chileno. Mecanismos y obstáculos para su implementación (Santiago, Ediciones Universidad Diego Portales, 2012) p. 234. 
el deber de "respeto y promoción" que tienen los órganos del Estado frente a los derechos contenidos en el Convenio (art. 5 inc. $2^{\circ}, \mathrm{CPR}$ ), sería "contradictorio sostener que los mismos órganos estatales puedan exceptuarse de su cumplimiento por la simple vía de una declaración de no-autoejecutabilidad"s7.

Por estas razones, la declaración de no autoejecutabilidad efectuada por TC sería difícilmente conciliable con lo establecido por el sistema de la OIT y el régimen constitucional chileno de tratados.

b) No obligatoriedad de la ratio descidendi de las sentencias del TC. Para decirlo con precisión desde un inicio: la ratio descidendi de los fallos del TC no es vinculante formalmente ${ }^{58}$, ni para el propio Tribunal Constitucional, ni para otros tribunales, ni menos para el Congreso Nacional o los órganos de la Administración ${ }^{59}$. Como apuntó el profesor Humberto Nogueira, "[e]l mismo legislador se negó a darle al Tribunal Constitucional el carácter de 'supremo intérprete de la Constitución' como asimismo dar carácter vinculante para los demás órganos del Estado a sus sentencias"60. Frente a esta realidad, el valor de las sentencias del TC y de sus razones o criterios de interpretación dependerán, en buena medida, "de cómo los tribunales los apliquen" ${ }^{1}$. No es trivial, entonces, el que la doctrina de la autoejecutabilidad/no autoejecutabilidad de las normas del Convenio en la práctica no haya sido respetada ni por el propio Tribunal, ni mayoritariamente seguida por los Tribunales Superiores de Justicia en lo que toca al art. $15 \mathrm{~N}^{\circ} 2$.

En relación a la jurisprudencia del TC, un somero repaso de sus

${ }^{57}$ Montt, Santiago y Matta, Manuel, Una visión panorámica al Convenio OIT 169 y su implementación en Chile, en Estudios Públicos (2011) 121, p. 172.

58 De acuerdo con la conocida escala de clasificación de los precedentes desarrollada por MacCormick y Summers, la vinculación formal es aquella en donde el no respetar el efecto vinculante de un precedente es ilegal y, en consecuencia, dicha decisión está sujeta a revocación por la vía de un recurso. Ver MaCCORMICK, Neil, Summers, Robert y Goodhart, Arthur (eds.), Interpreting Precedents. A Comparative Study (London, Routledge, 2016) pp. 554 y ss.

${ }^{59}$ Correa, Rodrigo, Informe de Constitucionalidad Convenio 169 sobre pueblos indígenas y tribales en países independientes, de la OIT (Santiago, Comisión de Verdad Histórica y Nuevo Trato, Subcomisión de Legislación, 2002) p. 12.

${ }^{60}$ Nogueria, Humberto, Las mutaciones de la Constitución producidas por via interpretativa del Tribunal Constitucional. ¿El Tribunal Constitucional poder constituido o poder constituyente en sesión permanente?, en Estudios Constitucionales 7(2009) 2, p. 427.

${ }^{61}$ Gómez, Gastón, Las sentencias del Tribunal Constitucional y sus efectos sobre la jurisdicción común (Santiago, Ediciones Universidad Diego Portales, 2013) p. 246. 
sentencias sobre la regla de consulta del art. $6 \mathrm{No}^{1}$ (a) en relación a las medidas legislativas, da cuenta cómo el propio Tribunal no ha seguido su propio precedente en la materia. En un inicio, el TC indicaba que la autoejecutabilidad del art. 6No1(a) implicaba que esta norma podía ser aplicada "sin otro trámite como fuente del derecho interno" 62 , lo que se traducía en que la entrada en vigencia del Convenio modificaba la Ley Orgánica Constitucional del Congreso Nacional ${ }^{63}$. No obstante, en sentencias sucesivas va mutando paulatinamente su postura al abordar la consulta a las medidas legislativas, haciendo cada vez más indistinguible el concepto de autojecutabilidad con el de no autoejecutabilidad ${ }^{64}$. Al fin, en su sentencia sobre la Ley de Pesca, el TC termina señalando que solo una vez que se haya fijado el procedimiento de consulta por el órgano correspondiente, "este Tribunal Constitucional estará en situación de controlar si (...) se han creado condiciones de participación igualitarias para los pueblos indigenas" "65. De esta forma, la autoejecutabilidad de la consulta requiere ahora de reglamentación previa para ser exigible y justiciable, la que era la definición de una regla no autoejecutable.

En la jurisprudencia de los Tribunales Superiores de Justicia, en la mayoría de los casos existentes se ha afirmado que la consulta del art. $15 \mathrm{No} 2$ es una obligación actualmente exigible en el ordenamiento jurídico nacional ${ }^{66}$. Así, ya en El Morro I, la Corte de Apelaciones de Antofagasta hacía referencia entre las normas que se debían cumplir, al "artículo 15 (...) debiendo consultarse a los interesados para determinar si los intereses de estos pueblos son perjudicados y en qué medida, antes de emprender o autorizar cualquier programa de prospección o explotación" ${ }^{67}$. De igual forma, en una

\footnotetext{
${ }^{62}$ Tribunal Constitucional, Rol No309/2000, 4 de agosto de 2000, Considerando $48^{\circ}$.

${ }^{63}$ Tribunal Constitucional, Rol No309/2000, 4 de agosto de 2000, Considerando $7^{\circ}$.

${ }^{64}$ Un análisis pormenorizado de esta secuencia puede encontrarse en CARMONA, Cristóbal y SCHÖNSTEINER, Judith, cit. (n. 11), pp. 7 y 8 . En un sentido similar, véase también GaldÁmez, Liliana, Comentario Jurisprudencial: La Consulta a los Pueblos Indígenas en la Sentencia del Tribunal Constitucional sobre Ley de Pesca Roles Nos. 2387-12-CPT y 2388-12-CPT, acumulados, en Estudios Constitucionales 11 (2013) 1, p. 632.

${ }^{65}$ Tribunal Constitucional, Rol No2387 - (2388)-12-CPT (acumuladas), 23 de enero de 2013, Considerando 23\%.

${ }^{66}$ Una excepción a ello sería el ya referido fallo de la Corte Suprema respecto al acuerdo entre Corfo y SQM. Ver Corte Suprema, Rol No 25.142-2018, 22 de abril de 2019, Considerando $8^{\circ}$.

${ }^{67}$ Corte de Apelaciones Antofagasta, Rol No618-2011, 17 de febrero de 2012, Considerando $10^{\circ}$; confirmada por la Corte Suprema, Rol N 2211-2012, 27 de abril de 2012.
} 
sentencia sobre la capacidad de una Comunidad Indígena para participar como tercero independiente en un juicio de constitución de servidumbres mineras, la Corte de Apelaciones de Copiapó expresó que la aplicación del Convenio era "imperativa", citando al efecto el art. $15 \mathrm{No}^{6}{ }^{68}$. Finalmente, la Corte de Apelaciones de Temuco se ha pronunciado en distintas oportunidades sobre esta norma. En un caso de extracción de áridos en territorio mapuche, la Corte derechamente declaró a la disposición del art. $15 \mathrm{No} 2$ como una "norma autoejecutable" 69 . Asimismo, a propósito de un procedimiento de constitución de concesión minera de exploración, este tribunal recientemente refirió que "el alcance de las normas del Código de Minería, debe ser interpretado conforme a los derechos que el Convenio 169 de la OIT garantiza a los Pueblos Originarios"70, modificando una regla establecida en el art. 34 del CM a partir de la aplicación del Art. $15 \mathrm{~N}^{\circ} 2$ del Convenio ${ }^{71}$.

Más allá del caso ya revisado del acuerdo Corfo/SQM, la Corte $\mathrm{Su}$ prema ha seguido la línea de las cortes de apelación en dos importantes fallos relativos a la industria minera. En El Morro II, al invalidar la segunda RCA de este proyecto, la Corte toma en consideración no solo la norma de consulta del art. $6 \mathrm{~N}^{\circ} 1$ (a) sino también la del art. $15 \mathrm{No}^{\circ} 2$, señalando que el Convenio "enfatiza la necesidad de consultar antes de la prospección o explotación de minerales"72. Adicionalmente, en Cerro Colorado (constitución de servidumbre), la Corte hace referencia a "la obligación directa, en el caso de los recursos minerales que le pertenecen al Estado, como es el caso de nuestra legislación, de mantener procedimientos de consulta con los pueblos interesados" 73 .

De esta forma, todo apunta a que la ratio descidendi de las sentencias del TC no se considera vinculante ni para el propio Tribunal, ni para otros órganos (judiciales y administrativos) del Estado.

${ }^{68}$ Corte de Apelaciones de Copiapó, Rol Civil 352-2012, 30 de abril de 2013, Considerando 6º ; confirmada por la Corte Suprema en causa Rol No3676-2013, 17 de junio 2013.

${ }^{69}$ Corte de Apelaciones de Temuco, Rol Protección No 52-2017, 23 de mayo de 2017, Considerando $4^{\mathrm{o}}$.

${ }^{70}$ Corte de Apelaciones de Temuco, Rol N Civil-297-2020, 28 de septiembre de 2020, Considerando $8^{\circ}$.

${ }^{71}$ Corte de Apelaciones de Temuco, Rol N Civil-297-2020, 28 de septiembre de 2020, Considerandos $11^{\circ}$ y $12^{\circ}$.

${ }^{72}$ Corte Suprema, Rol No11.299-2014, 7 de octubre de 2014, Considerando $26^{\circ}$.

73 Corte Suprema, Rol No6.628-2015, 4 de mayo de 2016, Sentencia de Reemplazo, Considerando $3^{\circ}$. 
c) Arbitrariedad en la determinación del carácter programático del art. $15 N^{\circ}$. El argumento del Tribunal Constitucional es arbitrario o carente de razonabilidad en varios sentidos. En el más elemental, lo es porque literalmente no proporciona ninguna razón para sustentar su categorización respecto de la consulta del Art. $15 \mathrm{No}^{74}$. Pero los problemas derivados de esta carencia de fundamentación se acentúan si se repara en que en esta sentencia el TC utiliza dos doctrinas distintas de autoejecutabilidad ${ }^{75}$. Por una parte, en el Capítulo IV de la sentencia expresa que las normas autoejecutables son "las que tienen el contenido y precisión necesarias que las habilita para ser aplicadas sin otro trámite como fuente del derecho interno" 76 . Por otra, en su análisis de los artículos $6 \mathrm{No}^{\circ} 1$ y art. $7 \mathrm{~N}^{\circ} 1$ hace depender la autoejecutabilidad de una norma de si ella está redactada en "términos perentorios" 77 o de "forma imperativa"78. Esta falta de consistencia deja abierta la interrogante de cuál fue, en definitiva, el criterio utilizado para determinar el carácter programático de la norma del art. 15No2. Empero, fuese cual fuere el criterio utilizado, el razonamiento del Tribunal presenta inconsistencias importantes.

Si el TC utilizó el primer criterio mencionado, esto es, el referido al "contenido y precisión" de las normas, tiene razón Jorge Contesse en que la norma del art. $6 \mathrm{~N}^{\circ} 1$ (a) tampoco debería haber sido considerada como autoejecutable, por cuanto es cuestionable que esta disposición "tenga un grado de especificidad tal que permita a un operador interno aplicarla sin más" ${ }^{\prime \prime}$. Si en cambio, se trató del criterio que evalúa la autoejecutabilidad en base a los términos "perentorios" o "imperativos" de su redacción, difícilmente puede sostenerse que existan diferencias significativas entre los términos de redacción de ambas reglas de consulta, como para deci-

${ }^{74}$ Tribunal Constitucional, Rol No309/2000, 4 de agosto de 2000, Considerando $70^{\circ}$.

${ }^{75}$ En la doctrina norteamericana se han llegado a identificar hasta cuatro doctrinas diferentes de autoejecutabilidad de los tratados. Ver VAZQUEZ, Carlos, The four doctrines of self-executing treaties, en The American Journal of International Law 89 (1995) 4, pp. 695-723.

${ }^{76}$ Tribunal Constitucional, Rol No309/2000, 4 de agosto de 2000, Considerando $48^{\circ}$.

${ }^{77}$ Tribunal Constitucional, Rol No309/2000, 4 de agosto de 2000, Considerando 7 o.

${ }^{78}$ Tribunal Constitucional, Rol No309/2000, 4 de agosto de 2000, Considerando $6^{\circ}$.

${ }^{79}$ Contesse, Jorge, El derecho de consulta previa en el Convenio 169 de la OIT. Notas para su implementación en Chile, en CONTESSE, Jorge (Ed.), El Convenio 169 de la OIT y el derecho chileno. Mecanismos y obstáculos para su implementación (Santiago, Ediciones Universidad Diego Portales, 2012) p. 204. 
dir que la del art. $6 \mathrm{~N}^{\circ} 1$ (a) era era autoejecutable y la del art. $15 \mathrm{No} 2$ no. Como notó Felipe Carrasco, a partir de una interpretación literal del art. 6 No1(a) también se podría concluir que dicha norma sería "programática", pues requiere que la consulta deba hacerse "mediante procedimientos apropiados" ${ }^{\circ 0}$. La razón para esta confusión puede encontrarse en el simple hecho que "virtualmente todos los tratados, sin importar cómo hayan sido redactados, permiten pero no requieren tanto una aplicación judicial directa como indirecta" ${ }^{\prime 1}$.

Una última crítica a la argumentación del Tribunal en este punto tiene que ver con que la referencia del art. $15 \mathrm{No} 2$ a que "los gobiernos deberán establecer o mantener procedimientos" de consulta, no implica necesariamente la dictación de reglamentos o modificaciones normativas. Como notaron Montt y Matta: "Aunque los procedimientos de participación en su sentido genérico pueden y deben ser regulados en detalle mediante ley o reglamento, dichas normativas no son esenciales para la existencia de ese derecho. Es decir (...) [l]a participación puede siempre ser estructurada directamente por los órganos públicos llamados a aplicar el Convenio 169 mediante procesos ad-hoc de participación" ${ }^{82}$. De hecho, esto fue lo que sucedió con los primeros PCPI en el SEIA. Abiertos durante la vigencia del antiguo reglamento del SEIA (D.S. No95/2001), el que no contemplaba referencia alguna a la consulta, dichos procesos se articularon aplicando directamente los principios del procedimiento administrativo.

Por esta y las demás las razones expuestas en este apartado, la decisión del TC en torno a calificar la norma del art. $15 \mathrm{No} 2$ como programática simplemente carece de fundamentos jurídicos para seguir siendo utilizada al momento de intentar justificar la falta de consulta de las concensiones mineras.

\section{La existencia procesos de consulta durante la evaluación ambiental de} proyectos mineros

De acuerdo a lo dispuesto por la Ley No19.300 y el RSEIA, deben ingresar al SEIA los "proyectos de desarrollo minero" sobre 5.000 ton/mes (art. 10 (i), Ley No19.300; art. 3(1), RSEIA). En caso que estos proyectos generen alguno de los efectos, circunstancias o características contemplados en los artículos 7, 8 y 10 del RSEIA que afecten directamente a uno o más Grupos Humanos Pertenecientes a los Pueblos Indígenas, el Servicio de

${ }^{80}$ Carrasco, Felipe, cit. (n. 49) p. 276.

${ }^{81}$ Vazquez, Carlos, Treaties as Law of the Land: The Supremacy Clause and the Judicial Enforcement of Treaties, en Harvard Law Review 122 (2008) p. 636. Traducción del autor.

${ }^{82}$ Montt, Santiago y Matta, Manuel, cit. (n. 57) p. 190. 
Evaluación Ambiental (SEA) deberá abrir un PCPI (Art. 85, RSEIA) ${ }^{83}$. A la fecha se han decretado procesos de consulta en 15 proyectos ingresados bajo esta tipología ${ }^{84}$.

Teniendo en cuenta lo anterior, un argumento que se ha esbozado -aunque de manera no tan nítida como los anteriores- es que la consulta a las concesiones mineras no sería procedente pues el momento en que se concreta el ejercicio de los derechos provenientes de las mismas es cuando su titular se somete al SEIA. Por consiguiente, se dice que es dentro de este procedimiento que resultaría aplicable la consulta. Quizás el ejemplo más patente de esta tesis se encuentra en el fallo de la Corte Suprema que desestimó la impugnación del Consejo de Pueblos Atacameños (CPA) del acuerdo entre Corfo y SQM.

La acción de protección incoada por el CPA y otras comunidades atacameñas buscaba la invalidación de los contratos suscritos entre Corfo y SQM -por los cuales, inter alia, se aumentaba la cuota de producción y comercialización de litio de SQM en el Salar de Atacama- por falta de consulta. La Corte rechaza esta acción en base a que la discusión propuesta por los grupos indígenas excedía la "naturaleza cautelar" del recurso de protección. El objetivo del recurso de protección, señala, es "otorgar cautela urgente ante la conculcación patente de derechos constitucionales en virtud de actos u omisiones (...) ilegales o arbitrarias" ${ }^{85}$. Este requisito, dice la Corte, no se configuraría en el caso de marras. Ello, toda vez que "los contratos impugnados a través de la presente acción constitucional, si bien aumentan la cuota para explotar, procesar y vender litio (...) lo cierto es que en forma alguna modifican las autorizaciones de carácter ambiental que actualmente tiene vigente $S Q M$ para la extracción de salmuera" ${ }^{\prime 6}$. Si la empresa decide aumentar la extracción, razona la Corte, deberá necesariamente modificar la RCA y será en esa oportunidad que se deberá determinar la procedencia de la consulta, tanto la del art. 6 como la del art. 15No2: "la obligatoriedad

${ }^{83}$ Para un análisis crítico de la implementación del PCPI en el SEIA, véase Carmona, Cristóbal, Evaluación ambiental, consulta indígena y el "desplazamiento" de los derechos de los pueblos indígenas, en Revista de Derecho U. de Concepción (2020) 248 pp. 199-232 [doi: 10.29393/RD248-17EACC10017].

${ }_{84}$ Sin un orden particular: "Actualización Proyecto Minero Quebrada Blanca", "Proyecto Minero Quebrada Blanca Fase 2", "Planta de Sulfato de Cobre Pentahidratado", "Monturaqui", "Continuidad Operacional Compañía Minera Zaldívar", "Proyecto Continuidad Operacional Cerro Colorado", "RT Sulfuros", "Sondajes de Prospección Paguanta", "El Morro", "Blanco", "Salares Blancos”, "Rajo Inca", "Actualización Arqueros" y "Desarrollo de Infraestructura y Mejoramiento de Capacidad Productiva de Collahuasi”.

${ }^{85}$ Corte Suprema, Rol No 25.142-2018, 22 de abril de 2019, Considerando 7o.

${ }^{86}$ Corte Suprema, Rol No 25.142-2018, 22 de abril de 2019, Considerando $8^{\circ}$. 
de la consulta indígena prevista en el artículo $\sigma^{\circ}$ letra a), debe definirse en el procedimiento previsto en la ley, que se vincula, indudablemente, a la eventual modificación de la RCA 226/2006, proceso ambiental en el que la autoridad deberá evaluar no sólo [sic] la procedencia de la consulta derivada de tal norma, sino que también analizar su factibilidad derivada de lo establecido en el numeral $15 N^{\circ} 2$ del referido convenio" ${ }^{87}$. Por esto es que, en opinión de la Corte, la situación planteada por los recurrentes "excluye la necesidad de adoptar medidas de cautela urgente" 88 . En este sentido, hasta que se intente modificar la RCA, "la situación del Salar de Atacama y de sus habitantes no sufre ningún cambio" 89.

Es verdad que esta sentencia se refiere a contratos y no al otorgamiento de concesiones de exploración y explotación minera -aunque uno de los contratos trataba del arrendamiento de pertenencias mineras, esto es, de concesiones de explotación-. Pero de todas formas, es claro que dichos contratos eran una forma de autorizar que se continuara con la explotación en el Salar y, por tanto, caían dentro del supuesto de hecho del art. $15 \mathrm{No}^{90}$. Por lo mismo, el fallo sirve para ilustrar la lógica que anima la argumentación analizada en este apartado. Esta postura parece suponer que el otorgamiento de autorizaciones para la exploración y explotación de recursos minerales existentes en territorio indígena no tendría efecto alguno sobre los derechos de los pueblos indígenas. De esta forma, solo cuando las prerrogativas que emanan de una concesión se materialicen en la obtención de una RCA, es que podrá haber una afectación real a los derechos indígenas y, en consecuencia, es que se deberá analizar la procedencia de la consulta.

Pero esta lógica, estimo, es incorrecta desde distintos puntos de vista. Desde una perspectiva puramente normativa, lo es por el hecho que existe una regla explícita que mandata la consulta antes de que se autorice "cualquier programa de prospección o explotación de los recursos existentes en sus tierras" (art. 15No2). Nótese que esta norma habla explícitamente de consulta previa a "autorizar cualquier programa" de prospección o explotación, y no antes del "inicio de la actividad" de prospección o explotación ${ }^{91}$. Además, según fue revisado anteriormente, el art. 15No2 ni siquiera requiere evidencia de posibles impactos para hacer procedente la consulta. Se trata, para decirlo nuevamente, de una regla objetiva: si los

\footnotetext{
${ }^{87}$ Corte Suprema, Rol No 25.142-2018, 22 de abril de 2019, Considerando $8^{\circ}$.

${ }^{88}$ Corte Suprema, Rol No 25.142-2018, 22 de abril de 2019, Considerando 90.

${ }^{89}$ Corte Suprema, Rol No 25.142-2018, 22 de abril de 2019, Considerando $9^{\circ}$.

${ }^{90}$ Carmona, Cristóbal y Schönsteiner, Judith, cit. (n. 11) pp. 21-23.

${ }^{91}$ Corte Superior de Justicia de Lima, Expediente No 14037-2013-0-1810-JRCI-10, 26 de abril de 2019, Considerando 13.2.
} 
recursos de titularidad estatal cuya exploración o explotación se autoriza se ubican en territorio indígena, entonces debe realizarse la consulta. Así, la consulta del art. 6 y la del art. $15 \mathrm{No} 2$ son dos obligaciones que responden a situaciones diversas y no es razonable concluir que la existencia de la primera haría prescindible la segunda. Al contrario, con independencia de lo que suceda en etapas posteriores, si en un inicio de la vida del proyecto se configura el supuesto de hecho de la norma del art. $15 \mathrm{No} 2$, el Estado está en la obligación de consultar a las comunidades del territorio. Por lo mismo, desde un punto de vista formal, consideraciones relativas a falta de “necesidad" de una consulta en un estadio inicial de la vida del proyecto minero por ya existir un PCPI en la evaluación ambiental, que es donde -se dice- realmente la industria podría producir impactos, no tendrían asidero jurídico.

No obstante, supongamos que por motivos de economía procesal ignoramos el mandato del Convenio y entendemos que no sería sensato duplicar los procesos de consulta a los que podría verse afecto un proyecto minero. Bastaría, diríamos, con una consulta previa a la autorización ambiental que requiere el proyecto. Pues bien, incluso elaborando desde este supuesto, el argumento es erróneo por al menos dos motivos. En primer lugar porque hay una serie de proyectos mineros que, aunque afecten derechos indígenas, no serán sometidos a un PCPI en el SEIA. Esto haría "necesaria" una consulta a nivel de concesiones. Recuérdese, como dato inicial, que solo deben ingresar a evaluación los "proyectos de desarrollo minero" sobre 5.000 ton/mes (art. 3(i)(1), RSEIA). Esto no es trivial. Como ha explicado Carrasco, por más que se pueda decir "que un proyecto minero de menos de 5.000 toneladas mensuales es de un impacto mínimo por el tamaño de producción, esto no es necesariamente cierto en el caso de los pueblos indígenas, ya que sí se puede producir afectación al sistema de vida de estos, más aún cuando en un mismo territorio indígena se pueda llegar a concentrar varios proyectos mineros de estas características"92. Junto a ello, debe considerarse que el art. 3 del RSEIA excluye a las "exploraciones" mineras de tener que ingresar al SEIA. Así, mientras que a las "prospecciones" las ubica dentro del concepto de "proyectos de desarrollo minero" para efectos de su ingreso a la evaluación (art. 3(i) RSEIA), excluye de dicho concepto a las “exploraciones". Aun cuando el reglamento efectúa una diferenciación conceptual entre ambas nociones, lo cierto es que la distinción entre "exploración” y "prospección” se reduce al número de plataformas que cada una considera. Por ejemplo, en las regiones del norte del país, si el proyecto contempla 40 o más plataformas

${ }^{92}$ Carrasco, Felipe, cit. (n. 49) p. 414. 
será una "prospección" y deberá ser evaluado ambientalmente (Art. 3(i) (2), inc. $1^{\circ}$, RSEIA). Si considera menos de 40 plataformas, en cambio, será una "exploración" y no deberá ser evaluado ambientalmente (Art. 3(i) (2), inc. $2^{\circ}$, RSEIA). Esto deja fuera del SEIA a proyectos que con 38 o 39 plataformas de sondaje que son claramente susceptibles de causar impacto ambiental, tal como quedó demostrado en el reciente fallo de la Corte Suprema en el caso Proyecto Cerro Márquez ${ }^{93}$. Pero incluso si el proyecto considera 40 o más plataformas e ingresa a evaluación, en la generalidad de los casos lo hará como Declaración de Impacto Ambiental (DIA). En consecuencia, a pesar de los impactos que genere, tampoco se someterá a un PCPI. De esta forma, parece claro que existe un número importante de proyectos mineros que quedan al margen del proceso de consulta del SEIA. En todos estos casos una consulta a las concesiones mineras no solo no duplicaría una consulta posterior a realizarse durante una evaluación ambiental, sino que puede ser la única instancia que las comunidades afectadas tengan para participar de un proceso toma de decisión sobre los recursos minerales existentes en su territorio.

En segundo lugar, aun en los casos en que sí hay un PCPI en el SEIA, la existencia de una consulta a nivel concesional y otra a nivel ambiental no sería redundante. Esto, ya que ambas tratan de temas y ámbitos diversos. Como es evidente a estas alturas, la consulta en el SEIA, aun cuando importante y necesaria, inevitablemente "llega tarde". En términos simples, el PCPI en el SEIA se concentra en la determinación de la idoneidad de las medidas de mitigación, reparación o compensación para hacerse cargo de los impactos significativos del proyecto. De esta forma, no existe un espacio para la discusión sobre cuestiones esenciales como el uso del territorio, el derecho para explotar o usar el recurso o el emplazamiento específico del proyecto $^{94}$. En este orden de ideas, la consulta a las concesiones mineras adquiere sentido en tanto permitiría a las comunidades influir en la toma de decisión sobre la vocación productiva que pretenden darle (o le están dando) a un determinado un territorio. Por ejemplo, visibilizando cómo les podría afectar la constitución de una concesión minera de exploración -con los respectivos derechos del concesionario a constituir servidumbres legales sobre los predios sirvientes ${ }^{95}$ - en áreas en las que se pretende desarrollar

${ }^{93}$ Corte Suprema, Rol No 2608-2020, 21 de septiembre de 2020.

${ }^{94}$ Ver Durán, Álvaro, cit. (n. 2) pp. 121 y 122; Astudillo, Luis, ¿Cumple Chile los estándares internacionales en materia de consulta a los pueblos indigenas?, en Estudios Constitucionales 15 (2017) 1, p. 144; y Carmona, Cristóbal, cit. (n. 83) p. 202.

${ }^{95}$ Es cierto que "la sola existencia de una concesión minera en un predio superficial no implica que por esa mera circunstancia el titular de la misma tenga facultad para (...) ejecutar trabajos de exploración y explotación” (Ossa, Juan Luis, cit. (n. 37) p. 
proyectos agrícolas o de conservación. En estos casos, como ha relevado la CEACR, la consulta tiene una gran importancia para "garantizar el derecho de los pueblos indígenas y tribales a decidir sus prioridades de desarrollo" ${ }^{96}$.

Vale subrayar, finalmente, que el argumento de que solo procedería consulta a nivel de la evaluación ambiental de proyectos mineros y no de las concesiones de exploración y explotación se vería refutado por la propia práctica nacional en materia de consulta. Según se mencionó en la introducción de este trabajo, actualmente el Ministerio de Energía está consultando a las concesiones de explotación de energía geotérmica. En caso que alguno de estos proyectos avance y la central de generación de energía geotérmica ingrese a evaluación ambiental (art. 3(c), RSEIA), no queda duda que, de cumplir con los requisitos del art. 85 del reglamento, procederá decretar la apertura de un PCPI durante su evaluación.

\section{LA REGLA DE CONSULTA DEL ART. 15No2 COMO NORMA APLICABLE A LAS CONCESIONES MINERAS}

Del análisis efectuado a estas cuatro razones comúnmente esgrimidas para justificar la falta de consulta a las concesiones mineras, se pueden sacar dos conclusiones de relevancia. La primera, es que ninguno de los argumentos revisados en el apartado anterior es jurídicamente plausible. Por ende, no existirían razones normativas de peso para no consultar las concesiones mineras. La segunda es que, en relación a este tópico, la regla de consulta a utilizar es la contenida en el art. $15 \mathrm{No} 2$, la que, se vio, es una obligación vigente y actualmente exigible en el ordenamiento

142; énfasis original) y que, para ello, se requerirá de la constitución de servidumbres. Empero, debe recordarse a su vez que estas son servidumbres "legales". "Ello significa que sin perjuicio de que pueden constituirse por acuerdo de los interesados, el titular del predio sirviente está obligado a tolerarlas aun contra su voluntad" (OsSA, Juan Luis, cit. (n. 37) p. 508). Junto a ello, se debe tener en cuenta que muchas veces la exploración y explotación minera en el norte de Chile se dará en terrenos fiscales, los que son al mismo tiempo parte de un "territorio indígena". En otras palabras, se trata de terrenos que no están formalmente inscritos a nombre de la persona o comunidad indígena. En consecuencia, su participación en el procedimiento de constitución de servidumbres como tercero independiente presentará complejidades. Para una discusión e interesantes ideas sobre la constitución de servidumbres mineras sobre los "predios sirvientes indígenas", véase CARRASCO, Felipe, cit. (n. 49) pp. 369 y ss.

${ }^{96}$ OIT, Observación General (CEACR) - Adopción: 2008, Publicación: 98a reunión CIT (2009) Convenio sobre pueblos indígenas y tribales, 1989 (núm. 169) [visible en internet: [https://www.ilo.org/dyn/normlex/es/f?p=1000:13100:0::NO:1310 0:P13100_COMMENT_ID,P11110_COUNTRY_ID,P11110_COUNTRY_ NAME,P11110_COMMENT_YEAR:3066698,,,2008]. 
jurídico chileno. Por consiguiente, lo que corresponde ahora es analizar la aplicabilidad de esta norma respecto del regimen concesional minero ${ }^{97}$.

Una lectura del enunciado normativo del art. $15 \mathrm{No} 2$ muestra que el antecedente o supuesto de hecho de la regla especial de consulta puede desagregarse en tres elementos: (1) que se trate de recursos de titularidad estatal, o sobre de los cuales el Estado tenga derechos; (2) que estos recursos existan en las tierras de los pueblos indígenas; y (3) que respecto de estos, los gobiernos vayan a emprender o autorizar un programa de prospección o explotación. A continuación revisaré cada uno de estos elementos para mostrar cómo las concesiones mineras en Chile pueden ser subsumidas dentro del supuesto de hecho de la norma sin mayores dificultades. Concluiré este apartado (4) con un sucinto esbozo de cómo se podría hacer operativo este derecho.

\section{Titularidad estatal de los recursos}

En su art. $19 \mathrm{No}_{2} 4$ inciso $6^{\circ}$, la CPR indica que el Estado "tiene el dominio absoluto, exclusivo, inalienable e imprescriptible de todas las minas". Independientemente de las discusiones que se han suscitado en doctrina en relación al tipo de dominio que detenta el Estado sobre las minas, si "patrimonial" ${ }^{8}$ o "público especial" "99, en virtud de esta norma constitucional -que significó desechar la propuesta de "dominio eminente" sugerida por la Comisión de Estudio de la Nueva Constitución Política ${ }^{100}$ es manifiesto que los recursos minerales en Chile son de titularidad estatal y, por ende, que se cumple con el primer supuesto de hecho de la regla especial

${ }^{97}$ Para una versión preliminar de este análisis, pero enfocado a las servidumbres mineras, véase CARMONA, Cristóbal, El deber de consultar las concesiones y servidumbres mineras: un comentario a la sentencia Rol No91-2017 (acumuladas 92-2017 y 932017) de la Corte de Apelaciones de Copiapó, en Revista de Derecho (Coquimbo) 26 (2019) [doi: https://doi.org/10.22199/10.22199/issn.0718-9753-2019-0019].

98 Pfeffer, Emilio, Naudon del Río, Alberto y Verdugo, Mario, Análisis Constitucional del Proyecto de Ley que establece una Regalía Ad-Valorem y Crea un Fondo de Innovación para la Competitividad (Santiago, Informe en Derecho sin publicar, 2004) p. 24.

${ }^{99}$ Lira, Samuel, cit. (n. 25) pp. 40-43.

${ }^{100}$ Precht, Jorge, Naturaleza Juridica del Dominio del Estado sobre las Minas y de la Concesion Minera en la Constitución de 1980, en Revista Chilena de Derecho 10 (1983) pp. 739-741. 
de consulta. Esto ha sido ratificado tanto por la Corte Suprema ${ }^{101}$ como por la Corte de Apelaciones de Temuco ${ }^{102}$ relación al mismo art. $15 \mathrm{No}^{\circ} 2$.

\section{Existencia de los recursos en territorio indígena}

El segundo elemento demanda que estos recursos del subsuelo de titularidad estatal existan en las "tierras" de los pueblos indígenas. Por mandato expreso del art. $13 \mathrm{No} 2$ del Convenio, cuando el art. $15 \mathrm{No} 2$ habla de "tierras", estas comprenden el concepto de "territorio", esto es, "la totalidad del hábitat de las regiones que los pueblos interesados ocupan o utilizan de alguna otra manera". Por lo mismo, no se requiere que los recursos se encuentren dentro de propiedad inscrita de una persona o comunidad indígena, ni menos que sea dentro de una propiedad con "calidad indígena" de acuerdo al art. 12 de la Ley Indígena. Basta con que estén presentes en un espacio territorial que los pueblos utilicen de alguna manera, sea material o simbólicamente ${ }^{103}$. Un aspecto interesante a destacar es que en este caso no se exige que este espacio sea ocupado "tradicionalmente", sino simplemente "de alguna otra manera".

En Chile, la jurisprudencia judicial y administrativa ha reconocido directa e indirectamente como parte de un "territorio indígena" tanto aquellas tierras de ocupación histórica que se encuentran en proceso de regularización ante Bienes Nacionales, como las Áreas de Desarrollo Indígena ${ }^{104}$.

${ }^{101}$ Corte Suprema, Rol No6.628-15, de 4 de mayo de 2016, Sentencia de Reemplazo, Considerando $3^{\circ}$ (“(...) la obligación directa, en el caso de los recursos minerales que le pertenecen al Estado, como es el caso de nuestra legislación, de mantener procedimientos de consulta con los pueblos interesados").

${ }^{102}$ Corte de Apelaciones de Temuco, Rol N ${ }^{\circ}$ Civil-297-2020, 28 de septiembre de 2020, Considerando 10॰ ("el artículo $15 N^{\circ} 2$ del Convenio 169 de la Organización Internacional del Trabajo, promulgado en nuestro país con posterioridad al Código de Minería, dispone que en caso de que pertenezca al Estado la propiedad de los minerales o de los recursos del subsuelo, cuestión que se cumple en nuestro país como asi lo explicita el inciso primero del artículo 1 del Código de Minería (...)")

${ }^{103}$ Para una análisis pormenorizado de la jurisprudencia de la Corte Suprema en materia de territorio, véase FAUNDES, Juan Jorge, Convenio $N^{\circ} 169$ de la OIT en la jurisprudencia de la Excelentísima Corte Suprema en Chile. Tendencias y debates en materia de propiedad y derecho al territorio, 2015 [visible en internet: http://decs.pjud. cl/Documentos/Academicos/Tendencias_Jurisprudenciales_Convenio169.pdf]

${ }^{104}$ Ver, Corte de Apelaciones de Antofagasta, Rol No235-2013, 28 de agosto de 2013, Considerando 34º; Corte Suprema, Rol No 14.003-13, 15 de mayo de 2014, Considerando 7o; Corte Suprema, Rol No6.628-15, 4 de mayo de 2016, Sentencia de Reemplazo, Considerando 40; Contraloría General de la República, Dictamen No 25667, 27 de septiembre de 2019; y Corte de Apelaciones de Antofagasta, Rol No14-2019, 30 de octubre de 2020.citx 
3. Que los gobiernos otorguen autorizaciones para la exploración y explotación de los recursos

El tercer elemento del supuesto de hecho de la regla del art. $15 \mathrm{~N}^{\circ} 2$ se refiere a que los gobiernos "autoricen" que particulares puedan realizar programas de prospección o explotación de los recursos naturales existentes en territorio indígena. A primera vista, la concesión minera en Chile no presentaría problemas para ser subsumida dentro de esta clase de medidas. Recuérdese que, una vez constituida la concesión por resolución de los tribunales ordinarios de justicia (art. 19No24, inc. $7^{\circ}, \mathrm{CPR}$ ), el concesionario tiene, entre otros derechos, la facultad exclusiva de catar y cavar en tierras de cualquier dominio dentro de los límites de la concesión (art. 7º, Ley Orgánica Constitucional de Concesiones Mineras (LOCCM)), a que se constituyan las servidumbres convenientes a la exploración y explotación mineras (art. 8, LOCCM) y, al fin, "a explorar y explotar libremente las minas sobre las cuales recae su concesión y a realizar todas las acciones que conduzcan a esos objetivos" (art. 11, LOCCM). Por ende, las concesiones de exploración y explotación mineras serían verdaderas "autorizaciones" para llevar a cabo programas de exploración y explotación minera.

Con todo, es posible prever al menos dos objeciones a esta conclusión. La primera, tiene que ver con el vocablo "prospección" que utiliza la versión en español del art. $15 \mathrm{~N}^{\circ} 2$. Según se ha visto en la sección (II.4), el ordenamiento jurídico nacional establece una diferencia entre "exploración" y "prospección", entendiendo que la primera es una fase previa a la segunda (art. 6, Reglamento de Seguridad Minera (D. 132/2002, Ministerio de Minería); y art. 3(i)(2), RSEIA). Por ende, se podría argumentar que el art. $15 \mathrm{No} 2$ no demanda una la consulta a las concesiones de exploración como se ha venido argumentando, sino que esta procedería al momento de evaluar el respectivo proyecto de prospección minera en el SEIA. Esto, estimo, no es correcto, como mostraré a continuación.

De partida, debe tenerse claro que la interpretación de los tratados internacionales opera sobre la base de que sus normas tienen un "significado autónomo"; esto es, que su significado es aquel que se deriva de la aplicación de las reglas de la CVDT y no depende de las diversas distinciones que se pueden encontrar en las legislaciones nacionales ${ }^{105}$. En base a esto, si se examinan las versiones del Convenio en sus dos idiomas auténticos, inglés y francés (art. 44), se puede ver que mientras la versión inglesa habla de "exploration", la francesa utiliza "prospection". En su sentido corriente

${ }^{105}$ Gardiner, Richard, Treaty Interpretation (Second Edition, New York, Oxford University Press, 2015) pp. 32-35. En este sentido, vale tener en cuenta que mientras en Chile "prospección" supone una fase posterior a la "exploración", en legislaciones como la peruana o la boliviana el orden es el inverso. 
ambos términos hacen referencia a acciones relativas a una búsqueda inicial o exploratoria de recursos naturales. Interpretados a la luz del objeto y fin del Convenio como lo requiere el art. 31 No 1 de la CVDT, lo más plausible es entender que cualquiera de estos dos términos denotan a las etapas iniciales de exploración de un proyecto minero. El objeto y fin del Convenio, según se desprende de su Preámbulo ${ }^{106}$ y ha sido identificado por la doctrina ${ }^{107}$, es doble: que los pueblos indígenas puedan mantener y desarrollar sus identidades y puedan ejercer control sobre sus propias formas de vida. Como es evidente, ambos objetivos se cumplen de mejor manera cuando las comunidades son "involucradas lo antes posible en el proceso" 108 , participando "desde las primeras etapas de la elaboración o planificación de la medida propuesta”"109. Así, puede concluirse que cuando la versión en español del Convenio habla de "prospección", se está refiriendo a las autorizaciones iniciales del proyecto minero que, en el caso chileno, estaría dado por las concesiones de exploración. Por lo demás, así lo ha entendido la CEACR en sus diversas observaciones y solicitudes directas a Chile, al requerir que se tomen medidas para asegurar la consulta a las "concesiones de exploración o explotación mineras"

La segunda objeción posible a la aplicación del art. 15No2 a las concesiones mineras se refiere a que esta disposición habla de autorizaciones que expiden los "gobiernos". En razón de ello, se podría pensar que esta norma solo abarcaría aquellas autorizaciones de exploración/explotación de naturaleza administrativa. Por consiguiente, si se entiende que la resolución que otorga las concesiones mineras es de naturaleza judicial, estas conce-

${ }^{106}$ Párrafo Preambular No4: "Reconociendo las aspiraciones de esos pueblos a asumir el control de sus propias instituciones y formas de vida y de su desarrollo económico y a mantener y fortalecer sus identidades, lenguas y religiones, dentro del marco de los Estados en que viven".

107 Ver, por ejemplo, Rombouts, Sebastiaan, The Evolution of Indigenous Peoples' Consultation Rights under the ILO and U.N. Regimes, en Stanford Journal of International Law, 53 (2017) p. 183 y CABRERA, María, cit. (n. 41) p. 60.

${ }_{108}$ OIT, Informe del Comité establecido para examinar la reclamación en la que se alega el incumplimiento por Ecuador del Convenio sobre pueblos indigenas y tribales, 1989 (núm. 169), presentada en virtud del artículo 24 de la Constitución de la OIT por la Confederación Ecuatoriana de Organizaciones Sindicales Libres (CEOSL), (GB.277/18/4):(GB.282/14/2), 2001 [visible en internet:[https://www. ilo.org/dyn/normlex/es/f?p=1000:50012:0::NO:50012:P50012_COMPLAINT_ PROCEDURE_ID,P50012_LANG_CODE:2507223,es:NO]

${ }^{109}$ Corte IDH, Caso del Pueblo Indígena Kichwa de Sarayaku, 27 de junio de 2012, párr. 167.

${ }^{110}$ Ver OIT, cit. (n. 6). 
siones caerían fuera del supuesto de hecho de la norma ${ }^{111}$. Este argumento es importante, por lo que vale analizarlo con detención.

Como se puede observar, la objeción homologa el término "gobiernos" con "administración". Aunque esta equiparación es plausible, estimo que no es adecuada. Volvamos a las dos versiones auténticas del Convenio, la inglesa y la francesa. Estas utilizan los términos "government" y "gouvernements", respectivamente. A diferencia de lo que ocurría con la voz "prospección", en el caso de "gobiernos" los significados de ambas versiones no son necesariamente coincidentes. En su acepción inglesa, "government" puede presentar un sentido amplio que abarca a los tres poderes del Estado - "the three branches of government", como se conoce en el derecho constitucional norteamericano-. En francés, en cambio, "gouvernements" suele circunscribirse a la autoridad administrativa. Ante esta diferencia, estimo que debe preferirse jurídicamente la acepción en donde "gobiernos" involucra a los tres poderes del Estado, según arroja una interpretación siguiendo las reglas de la CVDT.

En primer lugar, situando el término en el contexto del tratado, debe recordarse que la regla general de consulta del art. 6 también utiliza el vocablo "gobiernos", al señalar que: "los gobiernos deberán (...) consultar a los pueblos interesados (...) cada vez que se prevean medidas legislativas o administrativas susceptibles de afectarles directamente". En esta norma es evidente que el concepto "gobiernos" excede aquel de "autoridad administrativa", puesto que la consulta se aplica también a las "medidas legislativas", las que deberán ser llevadas a efecto por el poder legislativo ${ }^{112}$. En Chile, así ha sido entendido desde incluso antes de la vigencia del Convenio ${ }^{113}$. La consideración al objeto y fin del tratado arroja una conclusión similar. Según se indicó ya, el objeto y fin del Convenio es que los pueblos indígenas puedan mantener y desarrollar sus identidades y puedan ejercer control sobre sus propias formas de vida. En vista a ello, la acepción amplia de "gobiernos" se encontraría más alineada con el objeto y fin del tratado al permitir una mayor protección de la identidad de estos pueblos, así como posibilitar un cierto grado de control sobre su propio desarrollo. Finalmente, seña-

${ }^{111}$ Ver, por ejemplo, Carrasco, Felipe, cit. (n. 49) p. 353.

112 Ante esto, alguien podría objetar que el art. 7 del RGC establece dentro las "medidas legislativas" a los anteproyectos de ley y anteproyectos de reforma constitucional iniciados por el Presidente de la República. Pero en estos casos, de lo que se trata en realidad es de "medidas administrativas" y no "legislativas" propiamente tales.

113 Ver Tribunal Constitucional, Rol No309-2000, de 4 de agosto de 2000, Considerando 60; y Tribunal Constitucional Rol No2387 - (2388)-12-CPT (acumuladas), de 23 de enero de 2013 , considerandos $18^{\circ}$ a $25^{\circ}$. 
lar que esta lectura se vería reforzada por una interpretación en función del "principio de efectividad" o effet utile. En el ámbito de los tratados de derechos humanos como el Convenio, este principio implica que "la interpretación de las disposiciones debe tener un efecto real en términos de las vidas concretas y reales de los individuos que son reconocidos como portadores de derecho en los tratados de derechos humanos"114. Por lo mismo, cuando el enunciado del art. $15 \mathrm{No} 2$ habla de autorizaciones que expidan los "gobiernos", debe comprenderse como refiriendo a cualquier órgano del Estado sea de carácter administrativo, legislativo o judicial. En consecuencia, debe concluirse que la regla especial de consulta del art. $15 \mathrm{No} 2$ es aplicable al régimen de las concesiones mineras en Chile.

\section{Lineamientos para la operativización de la consulta en el proceso de} otorgamiento de concesiones mineras

Cumpliéndose los tres elementos del supuesto de hecho de la norma, no parece haber duda que normativamente las concesiones mineras debiesen consultarse de manera previa a su otorgamiento, aun sin la existencia de una modificación legal o reglamentaria al respecto -aunque esto último sería, sin dudas, preferible-. En otras palabras, esto implica reconocer que los derechos de los pueblos indígenas "han modificado las reglas para hacer minería" 115 , creando de por sí "un nuevo marco regulatorio"116. " $[E] n$ este contexto -como ha señalado la Corte de Apelaciones de Temuco- el alcance de las normas del Código de Minería, debe ser interpretado conforme a los derechos que el Convenio 169 de la OIT garantiza a los Pueblos Originarios" $" 11$. En base a esta premisa, quisiera concluir esbozando, aunque sea de manera muy preliminar, algunos puntos sobre qué modificaciones supondría la aplicación del derecho a consulta al procedimiento concesional. Específicamente, estimo que la realización de un PCPI en el régimen concesional minero modificaría las obligaciones de los órganos intervinientes en el proceso de constitución de concesiones en al menos tres instancias.

Una vez realizados los primeros trámites desde la presentación del escrito con que se inicia el procedimiento de concesión minera de exploración (pedimento) o de explotación (manifestación), el juez debe remitir el expediente al Servicio Nacional de Geología y Minería (Servicio) para

${ }^{114}$ ÇALI, BaŞak, Specialized Rules of Treaty Interpretation: Human Rights, Hollis, Duncan (Ed.), The Oxford Guide to Treaties (Oxford, Oxford University Press, 2012) p. 539.

${ }^{115}$ Carrasco, Felipe, cit. (n. 49) p. 17.

116 Carrasco, Felipe, cit. (n. 49) p. 18.

${ }^{117}$ Corte de Apelaciones de Temuco, Rol N Civil-297-2020, 28 de septiembre de 2020, Considerando $8^{\circ}$. 
que informe sobre los aspectos técnicos que le encomienda la normativa sectorial (art. 57 y 79 del CM). En esta instancia, con miras a dar cumplimiento al art. $15 \mathrm{~N}^{\circ} 2$, el Servicio debiese pronunciarse sobre si dentro de las áreas solicitadas existen elementos objetivos -tierras indígenas, ADI, derechos de aprovechamientos de agua, sitios de significación cultural, etc.- que puedan dar cuenta de la existencia de un territorio indígena. Para ello, el Servicio puede requerir informe a la Corporación Nacional de Desarrollo Indígena (CONADI), tal como lo hace actualmente el Ministerio de Energía durante la tramitación de las concesiones de exploración y explotación de energía geotérmica.

Segundo, si se estima que el área de la concesión coincide con un territorio indígena, el juez deberá abrir un PCPI, ordenándole al Servicio que lleve a cabo materialmente la consulta con las organizaciones indígenas presentes en el territorio. Para ello el Servicio puede ceñirse al proceso regulado por el RGC. En lo que toca al objeto de la consulta, este tendrá, entre otros, el fin específico de determinar si es que los intereses de estas organizaciones se verían afectados por las actividades de exploración y explotación proyectadas (arts. $7 \mathrm{No} 3$ y $15 \mathrm{No} 2$ ); el adoptar medidas para "proteger y preservar el medio ambiente" del territorio particular (art. $\left.7 N^{\circ} 4\right)$; y, al fin, aquel más general de "llegar a un acuerdo o lograr el consentimiento" acerca del otorgamiento (o no) de la concesión solicitada (art. 6No2).

Por último, el Servicio deberá remitir los resultados del procedimiento consultivo al juez. Estos involucrarán, por ejemplo, la identificación de sitios de significación cultural o de espacios destinados a la conservación y el etnoturismo, y cómo podrían verse afectados por las labores mineras de exploración o explotación. El juez decidirá con estos antecedentes en torno al otorgamiento o no de la concesión, a la modificación del área solicitada o alguna limitación a los derechos del concesionario para resguardar los derechos de estos pueblos. En síntesis, con la apertura de un PCPI: "cambia el carácter de procedimiento sumamente reglado de la concesión minera (...) y se matiza la falta de discrecionalidad del Tribunal, ya que este debe hacerse cargo argumentalmente del proceso de consulta, teniendo presente la legislación minera nacional y las obligaciones en materia de derechos humanos indígenas que ha adquirido el Estado de Chile a nivel internacional" ${ }^{118}$.

${ }^{118}$ Carrasco, Felipe, cit. (n. 49) p. 361. Valga la prevención de que el autor se está refiriendo a la aplicación de la hipótesis de consulta del art. 6 . 


\section{CONCLUSIONES}

Entendiendo que la implementación del Convenio supone un complejo proceso de disputa interpretativa sobre la naturaleza de las normas y su "traducción" local, en el presente artículo se abordó el caso de la (falta de) implementación del derecho a consulta en el otorgamiento de concesiones mineras. En particular, se analizó si la ausencia de consulta en esta materias podía entenderse como normativamente justificada o si, en cambio, se trata de un incumplimiento por parte del Estado desde el punto de vista del derecho interno.

Para ello se examinó, primero, las razones que han utilizado para justificar dicha omisión. Según se explicó, han sido cuatro principales argumentos que han sido aducidos por la dogmática, los tribunales y la Administración para dicho fin, a saber: que las instituciones jurídicas sectoriales existentes eran suficientes para cumplir con la consulta; que las resoluciones judiciales por las que se constituyen las concesiones no son medidas "administrativas" ni "legislativas" como lo requiere la regla general del art. $6 \mathrm{~N}^{\circ} 1$ (a); que la regla especial del art. $15 \mathrm{~N}^{\circ} 2$ no es directamente aplicable pues tendría el carácter de "no autoejecutable" o "programática"; y, finalmente, que un PCPI a nivel de concesiones no sería procedente dado que los proyectos mineros ya son consultados durante la evaluación ambiental. Del referido análisis surgieron dos conclusiones. Por una parte, que ninguna de estas razones resulta jurídicamente plausible para justificar la omisión de la consulta de las concesiones mineras. Por otra, que la norma aplicable a estos casos es la regla especial de consulta contenida en el art. 15No2 del Convenio, la que a su vez es actualmente exigible a los órganos del Estado.

Teniendo en cuenta lo anterior, se procedió a revisar con cierto detalle la aplicabilidad de esta norma al régimen concesional minero en Chile. Así, en base a los tres elementos que forman antecedente del art. $15 \mathrm{No} 2$, se pudo apreciar que el otorgamiento de concesiones mineras en Chile cae dentro del supuesto de hecho de esta regla especial de consulta. En consecuencia, en aquellos casos en que los recursos minerales se encuentren en territorio indígena, se "gatilla" para el Estado el llevar a cabo un procedimiento de consulta con las comunidades que habitan ese territorio. En función de lo anterior, entonces, se puede concluir que el Estado de Chile simplemente está incumpliendo la obligación de consulta a las concesiones mineras. 


\section{BiBLIOGRAFÍA}

Aguas, Javier y NahuelPan, Héctor, Los limites del reconocimiento indígena en Chile neoliberal. La implementación del Convenio 169 de la OIT desde la perspectiva de dirigentes Mapuche Williche, en CUHSO 29 (2019) 1, pp. 108-130.

Aninat, Isabel, Los desafíos pendientes del Convenio 169, en Puntos de Referencia (2014) 369.

Astudillo, Luis, ¿Cumple Chile los estándares internacionales en materia de consulta a los pueblos indígenas?, en Estudios Constitucionales 15 (2017) 1, pp. 129-152.

Barros, Alonso y SchönsteIner, Judith, Diligencia debida: Proyectos de inversión, propiedad sobre los recursos naturales y consulta libre, previa e informada a los pueblos y comunidades indígenas concernidos, en VIAL, Tomás (ed.), Informe Anual sobre Derechos Humanos en Chile 2014 (Santiago, Ediciones UDP, 2014).

Bermúdez, Jorge y Hervé, Dominique, La jurisprudencia ambiental reciente: tendencia al reconocimiento de principios y garantismo con los pueblos indígenas, en Anuario de Derecho Público (Santiago, Ediciones Universidad Diego Portales, 2013) pp. 237-255.

Cabrera, María, The Requirement of Consultation With Indigenous Peoples in the ILO: Between Normative Flexibility and Institutional Rigidity (Leiden, Brill Nijhoff, 2017).

Calderón, Matías, et al., Gran minería y localidades agrícolas en el norte de Chile: comparación exploratoria de tres casos, en Chungará. Revista de Antropología Chilena 48 (2016) 2, pp. 295-305.

ÇALI, Başak, Specialized Rules of Treaty Interpretation: Human Rights, Hollis, DUNCAN (Ed.), The Oxford Guide to Treaties (Oxford, Oxford University Press, 2012).

Carmona, Cristóbal, The Road Less Travelled: The Duty to Consult and The Special Rule of Article 15.2 of ILO Convention 169 in the Case of Geothermal Energy Concessions in Chile, en Journal of Energy \& Natural Resources Law 35 (2017) 4, pp. 485-501 [doi: https://doi.org/10.1080/02646811.2017.1355966].

Carmona, Cristóbal, El deber de consultar las concesiones y servidumbres mineras: un comentario a la sentencia Rol No91-2017 (acumuladas 92-2017 y 93-2017) de la Corte de Apelaciones de Copiapó, en Revista de Derecho (Coquimbo) 26 (2019) [doi: https://doi.org/10.22199/10.22199/issn.0718-9753-2019-0019].

Carmona, Cristóbal, Evaluación ambiental, consulta indígena y el "desplazamiento" de los derechos de los pueblos indigenas, en Revista de Derecho U. de Concepción (2020) 248, pp. 199-232 [doi: 10.29393/RD248-17EACC10017].

Carmona, Cristóbal y Schönsteiner, Judith, Amicus Curiae del Centro de Derechos Humanos de la Universidad Diego Portales, en el caso "Asociación Indígena Consejo de Pueblos Atacameños/Sqm Potasio S.A.”, 2018 [visible en internet:: http://www.derechoshumanos.udp.cl/derechoshumanos/images/ Carmona_Schonsteiner_Amicus_Caso_SQM_2018.pdf].

CARRASCO, Felipe, El derecho minero ante la normativa indigena nacional e internacional (Santiago, Ediciones Jurídicas de Santiago, 2017).

Contesse, Jorge y Lovera, Domingo, El Convenio 169 de la OIT en la jurisprudencia chilena: prólogo del incumplimiento, en Anuario de Derecho Público (Santiago, Editorial Universidad Diego Portales, 2011) pp. 127-151. 
Contesse, Jorge, El derecho de consulta previa en el Convenio 169 de la OIT. Notas para su implementación en Chile, en CONTESSE, Jorge (Ed.), El Convenio 169 de la OIT y el derecho chileno. Mecanismos y obstáculos para su implementación (Santiago, Ediciones Universidad Diego Portales, 2012), pp. 191-228.

Correa, Rodrigo, Informe de Constitucionalidad Convenio 169 sobre pueblos indigenas y tribales en paises independientes, de la OIT (Santiago, Comisión de Verdad Histórica y Nuevo Trato, Subcomisión de Legislación, 2002).

Donoso, Sebastián, Empresas y comunidades indígenas: el nuevo escenario que plantea el Convenio 169 de la OIT, en Temas de la agenda Pública 9 (2014) 73, pp. 3-20.

Durán, Álvaro, El derecho a consulta de los pueblos indígenas en el Sistema de Evaluación de Impacto Ambiental chileno, su estándar a la luz de la jurisprudencia nacional e internacional, en Revista de Derecho Universidad Finis Terrae II (2014) 2, pp. 101-161.

FAUNDES, Juan Jorge, Convenio $N^{\circ} 169$ de la OIT en la jurisprudencia de la Excelentísima Corte Suprema en Chile. Tendencias y debates en materia de propiedad y derecho al territorio, 2015 [visible en internet: http:/decs.pjud.cl/Documentos/Academicos/ Tendencias_Jurisprudenciales_Convenio169.pdf]

FAUNDES, Juan Jorge, Consulta indigena y centrales de generación hidroeléctrica de menos de $3 M W$ : desregulación riesgosa, a la luz del derecho fundamental a la identidad cultural de los pueblos indígenas, en Bozzo, Sebastián, REMESEIRo, Rebeca y EsIS, Ivette (Coords.), Memorias III Congreso Internacional de Regulación y Consumo (Santiago, Universidad Autónoma de Chile, RIL Editores, 2020) pp. 359-398.

Galdámez, Liliana, Comentario Jurisprudencial: La Consulta a los Pueblos Indígenas en la Sentencia del Tribunal Constitucional sobre Ley de Pesca Roles Nos. 2387-12-CPTy 2388-12-CPT, acumulados, en Estudios Constitucionales 11 (2013) 1, pp. 621-632.

Gardiner, Richard, Treaty Interpretation (Second Edition, New York, Oxford University Press, 2015).

Gómez, Gastón, Las sentencias del Tribunal Constitucional y sus efectos sobre la jurisdicción común (Santiago, Ediciones Universidad Diego Portales, 2013).

Guggiana, María, Fragilidad de los Derechos Mineros en Chile. Análisis Dogmático, Estudio de Casos (Santiago, Editorial Metropolitana, 2016).

Hervé, Dominique y Pérez, Raimundo (Coord.), Derecho Ambiental y Politicas Públicas. Cuadernos de Análisis Jurídico, Colección Derecho Ambiental (Santiago, Ediciones UDP, 2011).

Hervé, Dominique y Pérez, Sergio, Adecuación de la legislación interna a los estándares impuestos para la administración de recursos naturales, en CONTESSE, Jorge (Ed.), El Convenio 169 de la OIT y el derecho chileno. Mecanismos y obstáculos para su implementación (Santiago, Ediciones Universidad Diego Portales, 2012) pp. 15-101.

Hervé, Dominque, Justicia Ambiental y Recursos Naturales (Santiago, Ediciones Universitarias de Valparaíso, 2015).

LARSEN, Peter, Contextualising Ratification and Implementation: A Critical Appraisal of ILO Convention 169 From a Social Justice Perspective, en The International Journal of Human Rights 24 (2020) 2-3, pp. 94-111 [doi: https://doi.org/10.1080/1364 2987.2019.1677613].

Lira, Samuel, Curso de Derecho de Minería (Séptima edición actualizada, Santiago, Editorial Jurídica de Chile, 2016).

MacCormick, Neil, Summers, Robert y Goodhart, Arthur (eds.), Interpreting Precedents. A Comparative Study (London, Routledge, 2016). 
Merino, Roger, "The Cynical State: Forging Extractivism, Neoliberalism and Development in Governmental Spaces”, en Third World Quarterly 41 (2020) 1, pp. 58-76, [DOI: 10.1080/01436597.2019.1668264].

Meza-Lopehandía, Matías, El Convenio No169 sobre pueblos indígenas y tribales de la Organización Internacional del Trabajo, en AyLWIN, José (Coord.), Los pueblos indígenas y el derecho (Santiago, LOM, 2013) pp. 337-439.

MontT, Santiago y MatTa, Manuel, Una visión panorámica al Convenio OIT 169 y su implementación en Chile, en Estudios Públicos (2011) 121, pp. 133- 212.

Nogueria, Humberto, Las mutaciones de la Constitución producidas por vía interpretativa del Tribunal Constitucional. ¿El Tribunal Constitucional poder constituido o poder constituyente en sesión permanente?, en Estudios Constitucionales 7 (2009) 2, pp. 389- 427.

NúNEz, Manuel, Comentario a 'El derecho de consulta previa en el Convenio 169 de la OIT. notas para su implementación en Chile', en CONTESSE, Jorge (Ed.), El Convenio 169 de la OIT y el derecho chileno. Mecanismos y obstáculos para su implementación (Santiago, Ediciones Universidad Diego Portales, 2012) pp. 232-240.

Ossa, Juan Luis, Tratado de Derecho de Minería (Quinta Edición actualizada y ampliada, Santiago, Editorial Jurídica de Chile, 2012).

Pfeffer, Emilio, Naudon del Río, Alberto y Verdugo, Mario, Análisis Constitucional del Proyecto de Ley que establece una Regalía Ad-Valorem y Crea un Fondo de Innovación para la Competitividad (Santiago, Informe en Derecho sin publicar, 2004).

Precht, Jorge, Naturaleza Juridica del Dominio del Estado sobre las Minas y de la Concesion Minera en la Constitucion de 1980, en Revista Chilena de Derecho 10 (1983) pp. 727-779.

Rombouts, Sebastiaan, The Evolution of Indigenous Peoples' Consultation Rights Under the ILO and U.N. Regimes, en Stanford Journal of International Law, 53 (2017) pp. 169-224.

Urrejola, Antonia, Aplicación del Convenio No169 en Chile, en De Cea, Maite y Fuentes, Claudio (Eds.), La Consulta Indígena. Colombia-Perú-Chile (Santiago, RiL Editores, 2016) pp. 115-176.

Vazquez, Carlos, The Four Doctrines of Self-Executing Treaties, en The American Journal of International Law 89 (1995) 4, pp. 695-723.

VazQuez, Carlos, Treaties as Law of the Land: The Supremacy Clause and the Judicial Enforcement of Treaties, en Harvard Law Review 122 (2008) pp. 599-694.

Vergara, Alejandro, Sistema de Derecho Minero (Santiago, Thomson Reuters, 2013). Villiger, Mark, Commentary on the Vienna Convention on the Law of Treaties (Oxford, Oxford University Press, 2009). 